\title{
Free fat, surface fat and dairy powders: interactions between process and product. A review
}

\author{
Marie-Laure Vignolles, Romain JEANTET, Christelle LOPEZ, Pierre SCHUCK* \\ INRA, Agrocampus Rennes, UMR1253, Science et Technologie du Lait et de l'Euf, \\ 35042 Rennes, France
}

Received 18 December 2006 - Accepted 13 April 2007

\begin{abstract}
Nowadays, fat-filled spray-dried dairy powders have acquired an economic importance. Increasing the fat content leads to further quality implications such as off-flavors, and poor rehydration and flowing properties. However, the control of the drying operation and of the powder properties is still rather empirical in this case and few studies have focused on the whole issue up to now. This review aims at giving an overview of research work on fat-filled powders. The so-called "free fat" is often related to fat-filled powders, but the review also highlights the relevance of "surface fat" to powder physical properties. Quantitative and qualitative analytical techniques, mainly referring to free fat, are described here. This review focuses on the specific and combined influence of composition constituents (fat, protein, lactose and mineral elements) and process steps (such as heat treatments, homogenization, drying and storage) on physical properties of fat-filled powders (oxidation, wettability, dispersibility, solubility and flowing properties).
\end{abstract}

free fat / surface fat / spray drying / fat-filled dairy powders / functional properties

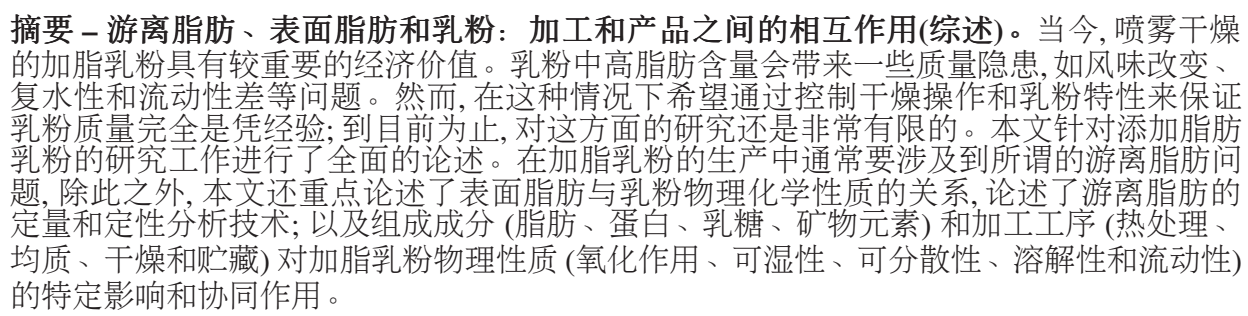

游离脂肪 / 表面脂肪 / 喷雾干燥 / 加脂乳粉 / 功能性

Résumé - Matière grasse libre, matière grasse de surface et poudres laitières enrichies en matière grasse : interactions procédé-produit. État de l'art. Les poudres laitières spray enrichies en matière grasse occupent aujourd'hui une place économique considérable. La présence de matière grasse entraîne des défauts de qualité majeurs tels que l'oxydation, de mauvaises propriétés de réhydratation et d'écoulement. Toutefois, le séchage par atomisation de ces poudres et la maîtrise de leurs propriétés d'usage restent assez empiriques, les études globales de la problématique étant

*Corresponding author (通讯作者): Pierre.Schuck@ rennes.inra.fr 
peu nombreuses. Cette revue se propose de dresser un état des connaissances sur les poudres laitières enrichies en matière grasse. La matière grasse dite "libre " est souvent associée à ce type de poudres, mais cette revue insiste également sur la notion de " matière grasse de surface " qui semble un paramètre parfois plus pertinent dans l'influence de leurs propriétés physiques. Les techniques analytiques quantitatives et qualitatives de la matière grasse dans les poudres laitières, principalement de la matière grasse libre, sont décrites. Cette revue prend en compte les constituants entrant dans la composition des produits (matière grasse, protéines, lactose et minéraux), les étapes de fabrication (principalement traitements thermiques, homogénéisation, séchage et stockage) et les propriétés physiques des poudres (oxydation, mouillabilité, dispersibilité, solubilité et écoulement), ainsi que les interactions entre ces différents paramètres.

matière grasse libre / matière grasse de surface / séchage par atomisation / poudre laitière enrichie en matière grasse / propriété fonctionnelle

\begin{abstract}
Abbreviations: ALA: $\alpha$-lactalbumin; AMF: anhydrous milk fat; BLG: $\beta$-lactoglobulin; CLSM: confocal laser scanning microscopy; CSS: corn syrup solids; DE: dextrose equivalent; DM: dry matter; DSC: differential scanning calorimetry; EU: European Union; FA: fatty acids; MFGM: milk fat globule membrane; M-starch: modified starch; NPC: native phosphocaseinate; N-starch: native starch; SDS-PAGE: sodium dodecyl sulfate polyacrylamide gel electrophoresis; SEM: scanning electron microscopy; TAG: triacylglycerols; TEM: transmission electron microscopy; $\mathrm{T}_{\mathrm{g}}$ :glass transition temperature; WMP: whole milk powder; WPC: whey protein concentrate; WPI: whey protein isolate; XPS: X-ray photoemission spectrometry.
\end{abstract}

\section{INTRODUCTION}

Milk is one of the most varying products of our diet with regard to its physical and physicochemical features, because of its very high water content ( 87 to $88 \%$ ).

As a consequence, men had to empirically develop technologies to both reduce the water content and create physicochemical conditions which allow milk stability in the residual water fraction. Early industrial scale dairy powders were manufactured in the 1850's but they incorporated subsidiary elements such as sugar, sulfuric acid or alkali [178]. Just and Hatmaker patented a roller drying process in 1902 [98]. Jensen and Grey developed and commercialized the first spray drying facility in 1913 [178]. After the end of the Second World War, roller drying became insufficient to dry the whole excess milk by-products and to meet the market's new needs [98]. Milk industry had to invest extensively in drying facilities and spray drying tended to predominate over roller drying in the 1970's thanks to technological improvements (e.g. the evaporation rate). Current facilities have become very complex and of a high technological level.
Dairy powders can be classified depending on their composition: skim, whole and fat-filled milk powders with a fat content of $0 \%, 26 \%$ and more than $26 \%$ respectively; casein and caseinate powders (e.g. sodium and calcium caseinate); whey powders (mostly sweet whey) and milk ingredients such as whey protein concentrate (WPC), whey protein isolate (WPI) and lactose [26,69].

From an economical point of view, whole milk powder (WMP) production (only milk fat) was up to 3.5 million tonnes in 2004 (see Fig. 1) [68]. China accounted for $25 \%$ of the production and used it for its own consumption; the European Union (E.U.) produced almost another fourth part. Adding New Zealand, Brazil, Argentina and Australia, the abovementioned countries represented $90 \%$ of worldwide production of WMP. More than half of the production was dedicated to the international trade: these quantities have doubled since 1990 to stabilize themselves at around 1.7 million tonnes in 2004 . New Zealand was the major supplier with one third of the exported volume; then, the E.U. accounted for almost 30\% of 

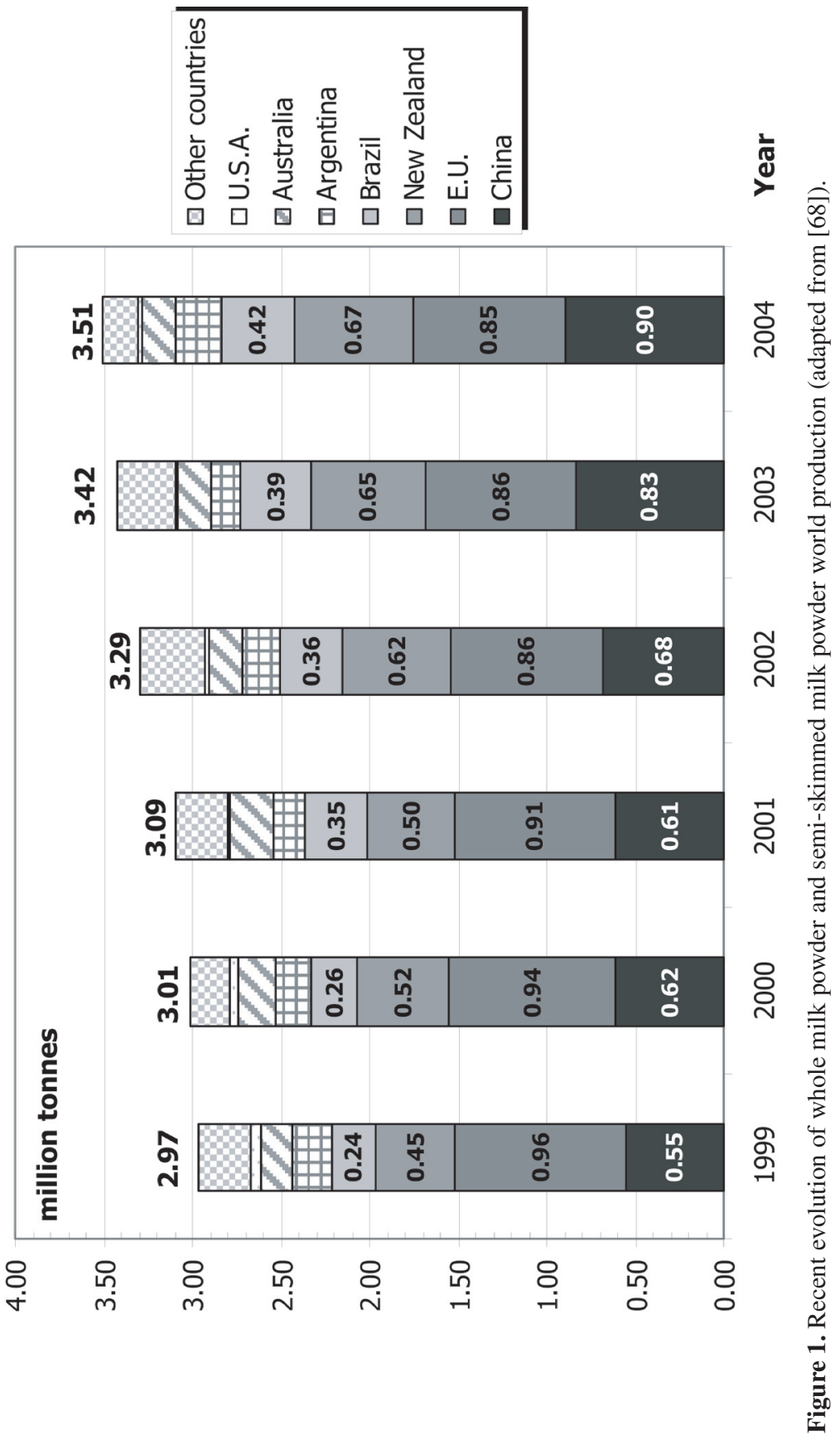
the international WMP market. Few data are available for milk ingredients. International trade of whey derivatives strongly increased last years; major suppliers were the E.U., Oceania and the United States.

To change a liquid dairy preparation into a powder means to remove almost all of its water content [178]. As a consequence, the drying process causes a range of structural and physicochemical modifications, which in turns influences the reconstitution and handling properties of dairy powders and their shelf-life. The aim of this review is to consider the composition of the concentrate and the drying process from the point of view of the socalled "free fat". Except for its special use in chocolate manufacturing, the latter is considered as a quality defect. The drying industry attributes to free fat a strong decrease in rehydration properties, flowability and a development of oxidation flavors.

Few recent studies have been published about fat-filled dairy powders issues and none of them considered the formation of free fat from the beginning to the end of the process, both varying composition and process parameters. Latest most complete work was assigned to Buma [15-23,25] but drying facilities and nature of the concentrates to dry have evolved a lot up to now.

After a short presentation of the fundamentals of fat stability, the present review intends to give a definition of free fat and describes the methods to quantify and observe the different forms of fat. The importance of each composition elements and the influence of each step of a dairy powder production process are then highlighted. A last part finally deals with the interactions between the product composition and the process parameters, and the influence of free fat and surface fat on the physical properties of fat-filled dairy powders.

\section{FUNDAMENTALS ABOUT EMULSIONS STABILITY AND THE FORMATION OF FREE FAT}

Lipids are a chemically heterogeneous group of compounds which are not watersoluble, but which are soluble in waterimmiscible organic solvents, e.g. alcohols and chloroform [58]. Triacylglycerols or triglycerides (TAG) are the major lipid class of natural fats and oils. They are fatty acid (FA) triesters of glycerol [59].

\subsection{Emulsions stability}

\subsubsection{A definition of emulsion}

An emulsion is a system where a liquid called the "dispersed phase" is dispersed as small droplets within another liquid called the "dispersing phase" or "continuous phase" [85]. The two liquids are little soluble or immiscible substances. Platon [132] cited the definition from the IUPAC (International Union of Pure and Applied Chemistry) which is the more exhaustive: "In an emulsion, liquid droplets and/or crystals are dispersed within another liquid medium". Fat droplets in dairy powders are often mentioned as encapsulated fat or oil (Fig. 2) [11, 54, 62-64, 75, $80,86,113,114,122,129,136-138,140,141$, $148,149,162,182,183]$.

As emulsions are thermodynamically instable dispersions, the system tends to minimize the surface free energy between the two phases. They may be considered as lyophobic colloids.

\subsubsection{Interaction energy}

The interaction energy between two fat globules or droplets is the free energy needed to bring two particles from an infinite distance apart closer to each 


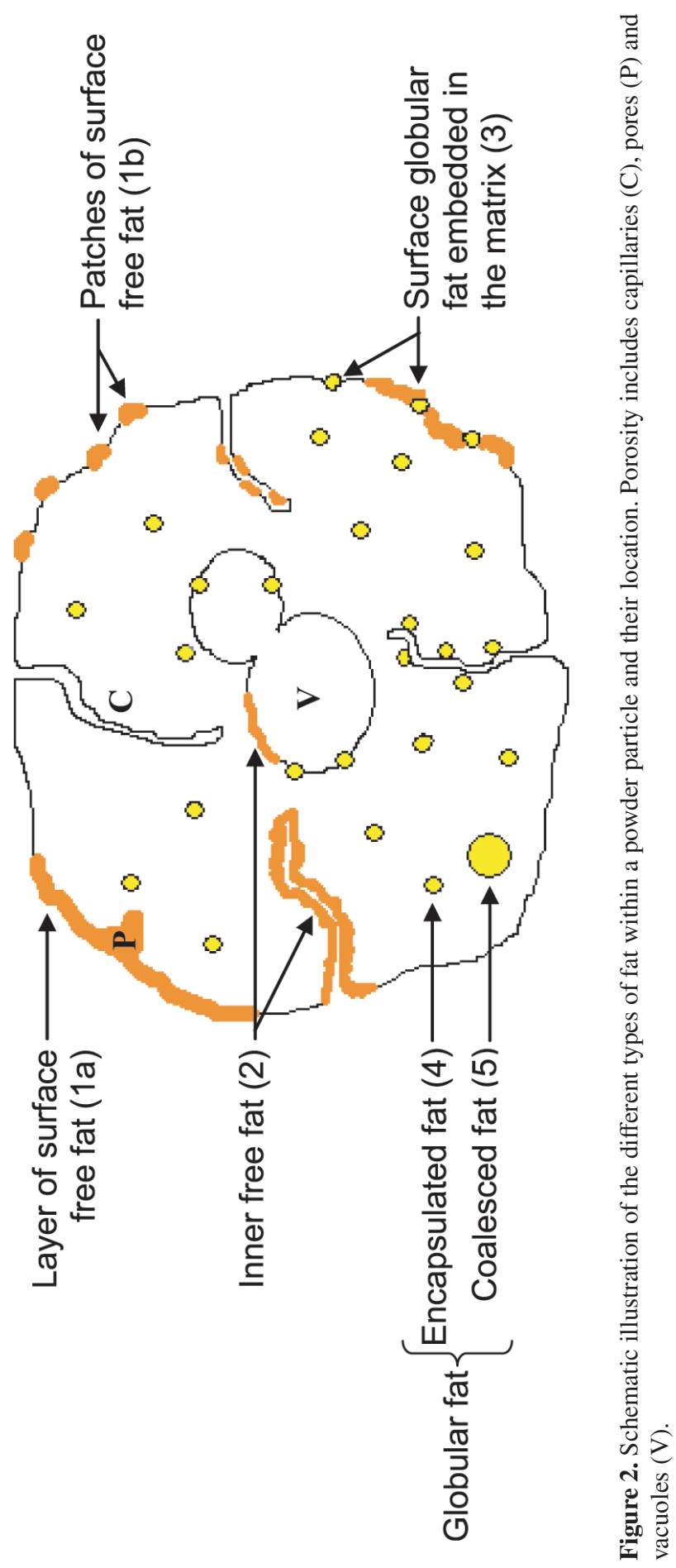


other [172]. Electrostatic repulsion, van der Waals attraction and steric repulsion mainly explain the stability against aggregation of such colloids. For instance, adsorbed proteins in homogenized milks result in steric repulsions which allow emulsion stability.

\subsubsection{Types of instability of emulsions}

Emulsion instability can be reversible or not and involves three ways: creaming, aggregation and total or partial coalescence (Fig. 3) [172]. These processes affect one another.

\subsubsection{Creaming}

Milk fat globules are able to rise spontaneously without any changes in their average size when milk is subjected to gravity or to a centrifugal force [172]. During the first step of creaming, a vertical concentration gradient of particles gradually establishes, then they form a layer rich in fat globules above the oil-in-water emulsion. The Stokes equation gives the rising velocity $v$ of fat globules:

$$
v=a\left(\rho_{\mathrm{p}}-\rho_{\mathrm{f}}\right) d^{2} / 18 \eta_{\mathrm{p}}
$$

where $a$ is the acceleration defining the field, $\rho_{\mathrm{p}}$ and $\rho_{\mathrm{f}}$ are the densities of the continuous and the dispersed phase respectively, i.e. plasma and fat, $d$ is the particle diameter of fat globules and $\eta_{\mathrm{p}}$ is the viscosity of the continuous phase. Thus, creaming can be delayed by:

(i) decreasing the particle size $(d)$ thanks to homogenization;

(ii) decreasing the difference between the two phases densities thanks to homogenization because of plasma protein adsorption at the surface of fat droplets;

(iii) increasing the viscosity $\eta_{\mathrm{p}}$ of the continuous phase [118].

\subsubsection{Aggregation}

However the presence of agglutinins (immunoglobulins that can act as bridges between fat globules) in cows' raw milk enhanced the rising speed at lower temperatures more than the Stokes equation predicts it [172]. This is the only kind of aggregation occurring with natural fat globules, the so-called "cold agglutination". Brownian motion and shearing are responsible for it while stirring makes it reversible. Heat treatments and homogenization can prevent this flocculation phenomenon.

\subsubsection{Coalescence}

Coalescence is not reversible because it consists in the flowing together of two fat globules or emulsions droplets into a larger one [172]. When two particles are very close to each other, the thickness of the film of the continuous phase between them can reach less than $10 \mathrm{~nm}$ and the film will thus rupture. Homogenizing can delay or prevent the coalescence to occur. If fat globules are closely pressed together, considerable coalescence can occur as it is observed when evaporating the water from cream or when spray-drying the latter. The presence of semicrystalline fat enhances the disruption of the film all the more since a mechanical stress is applied.

Partial coalescence (or clumping), where particles are linked by liquid fat bridges, generally leads to total coalescence. It is specific to milk fat.

\subsection{Towards a definition of free fat}

There is no consensus about what is free fat. This part aims to give a definition of free fat after considering the many approaches of the concept. 


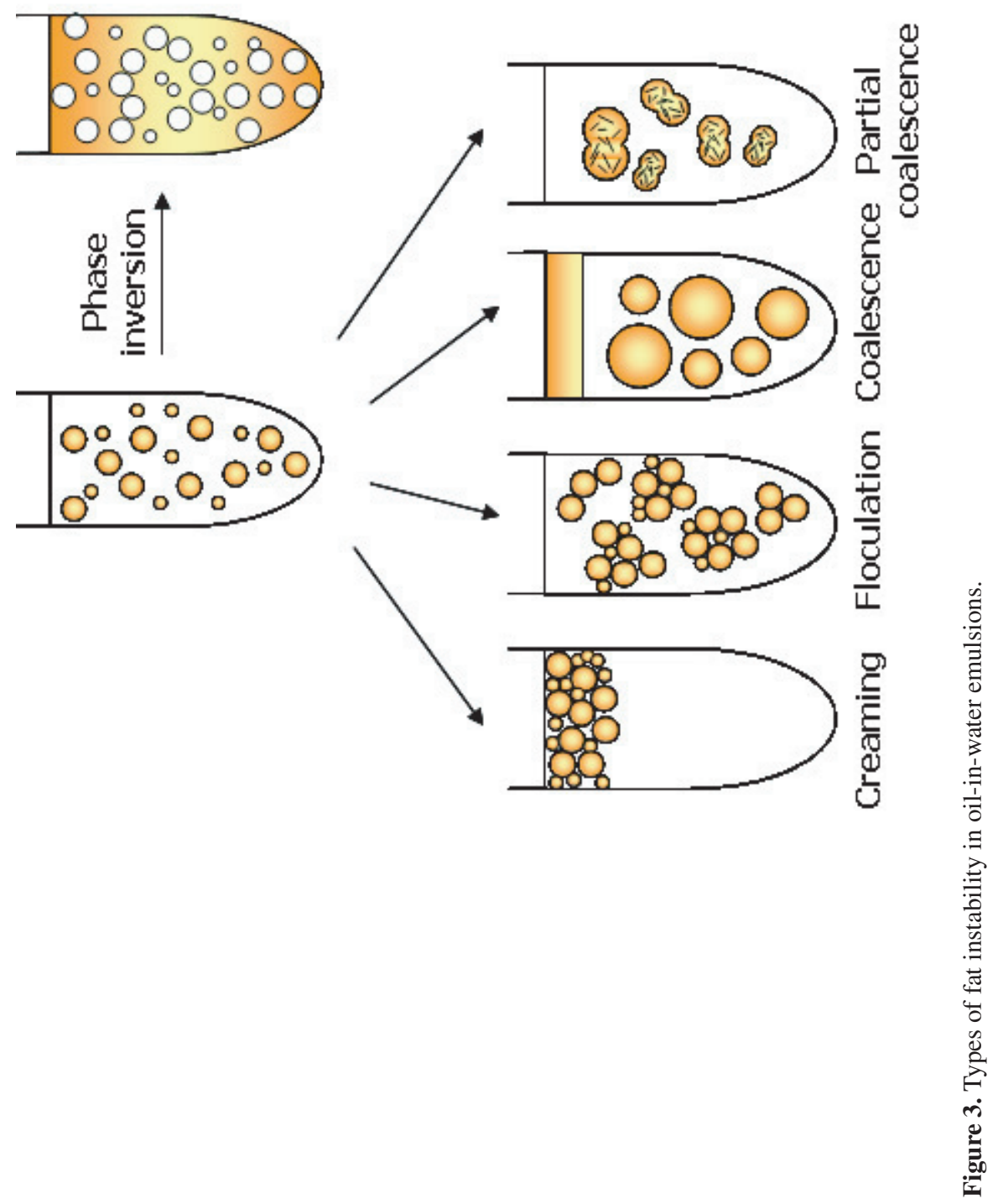




\subsubsection{Structural definition}

Free fat is the fat that is no longer emulsified [128, 167], i.e. that is non-globular as it was defined in cheeses such as Emmental cheese [94,96,97]. Buma [16] cited Holm et al. [65] as the first authors to mention the so-called "free fat" in their study of the qualitative deterioration of whole milk powders during storage. In milk, fat that is no longer entirely protected by a native membrane called the milk fat globule membrane (MFGM) (Fig. 4A) or a proteic film, and the released fat are common expressions to define free fat in the literature $[50,79,156,178]$. Free fat could be considered as an indirect measurement of milk fat globule damage $[157,158]$ or the deterioration level of the proteic coat of fat droplets but it would not represent all aspects of it [40]. For more details about evaluation of MFGM damage, see the recent review published by Evers [40]. If the coating membrane is deteriorated, it can no longer play its protective role towards the core fat against the physicochemical outer conditions. Neutral lipids are then able to be released and to spread through it [50].

It is now admitted that free fat is located both at the powder particle surface and within it, in the pores and capillaries created during the drying process (see Fig. 2) $[15,79,178]$.

\subsubsection{Biochemical definition}

Lindquist and Brunner [93] observed that free fat was slightly more concentrated in saturated FA, free FA, monoglycerides and phospholipids than encapsulated fat. A recent study confirmed this trend: free fat was slightly more concentrated in saturated FA from 6 to 8 carbon chain-length, and less concentrated in unsaturated FA, namely C16:1, C18:1, C18:2 and $\mathrm{C} 18: 3$ [82]. Furthermore, surface free fat contained slightly more saturated FA than inner free fat in a spray-dried cream powder; the trend was not significant in a spray-dried whole milk powder. Free fat was then supposed to be enriched in highmelting point TAG and the latter tended to accumulate at the powder particle surface. However thermal profiles from surface free fat, inner free fat and encapsulated fat indicated complex blends of TAG with melting points ranging from -40 to $40{ }^{\circ} \mathrm{C}$ [82]. In a contradictory study, The Truyen and Orsi [159] observed a greater proportion of unsaturated FA in the free fat fraction and of polar lipids in bound fat. The possible fractionation of lipids between free and encapsulated fat still needs further investigations.

\subsubsection{Method-dependent definition}

It should be noted that many publications still defined free fat as the solventextractable fat under controlled conditions [77, 82, 128, 156]. As each author adapted the method to its own applications, free fat was then an equivocal term. Furthermore Walstra [172] did not support the concept of free fat in milk and claimed that uncovered fat was impossible. Indeed, proteins would adsorb onto fat in about $10 \mathrm{~ms}$, i.e. as soon as the lipid fraction would come into contact with milk plasma.

We propose the following definition: free fat is fat (i) which is not entirely coated and stabilized by amphiphilic molecules, e.g. either by the MFGM composed by phospholipids and proteins or by a reconstituted coating of adsorbed proteins after some processing steps such as heat treatment and homogenization, or (ii) which is not entirely protected by a matrix composed by amorphous carbohydrates (e.g. lactose) and proteins during drying. It is located both at the surface and the inner parts of a powder particle. 


\section{(A) Natural milk fat globules \\ (0.2 - $10 \mu \mathrm{m}$; mean diameter $\sim 4 \mu \mathrm{m}$ )}

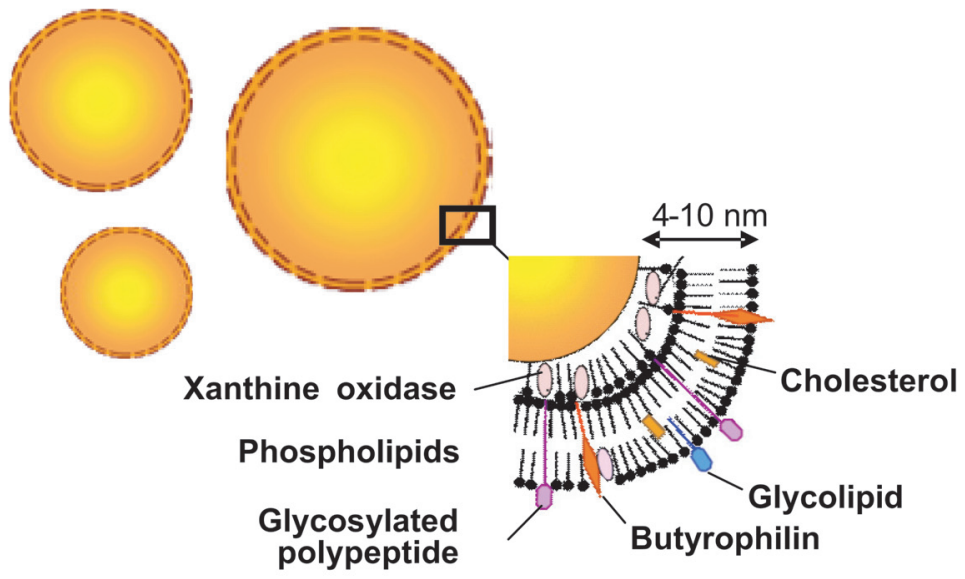

Milk fat globule membrane (MFGM)

\section{(B) Homogenized fat globules}

$(0.2-2 \mu \mathrm{m})$

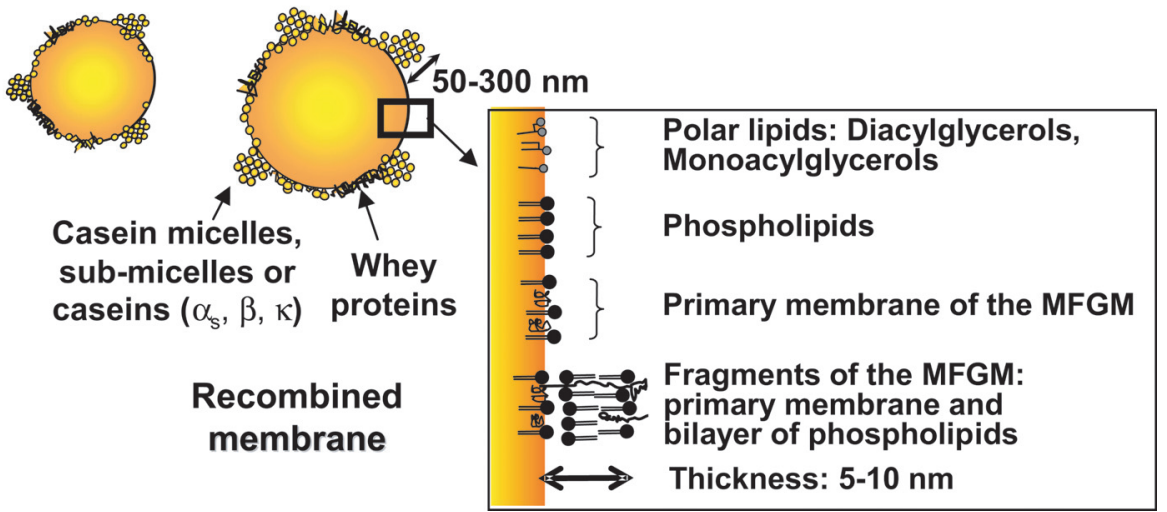

Figure 4. The milk fat globule membrane (A) before and (B) after mechanical damage, e.g. after homogenization (schemes are not to scale). 


\section{ANALYTICAL METHODS FOR THE ASSESSMENT OF FREE FAT AND SURFACE FAT}

\subsection{Quantitative methods}

\subsubsection{The solvent extraction method}

\subsubsection{General principle}

This method is the most commonly used to quantify free fat in dairy powders. Only fat that is not entirely protected as in the definition given above can be removed by the solvent. It gives an estimation of the efficiency of encapsulation of fat through the process [42]. It consists in adding a fixed volume of an organic solvent to a fixed weight of powder, then mixing them for a determined time. Then the suspension is filtered and the extraction is repeated as many times as necessary to recover all free fat. The latter is gravimetrically quantified after evaporation of the solvent. Free fat is usually expressed as a percentage of the total fat or sometimes as a percentage (w/w) of the powder, depending on the properties under consideration [17].

\subsubsection{Extraction parameters}

Extraction parameters considerably affect the amount of recovered free fat, sometimes up to a factor of $10[17,41,82]$. The kind of fat solvent did not influence free fat recovery, providing it was apolar. Benzene, petroleum ether, n-hexane, iso-octane, toluene, tert-butyl methyl ether and carbon disulphide gave comparable amounts of free fat. Carbon tetrachloride did not seem adapted because of its high density. Polar solvents were avoided since they led to the recovery of total fat $[17,41]$. They also involved the solubilization of amorphous lactose and often its crystallization $[1,79]$. Petroleum ether and hexane have been widely used for free fat extraction $[7,9,15-23,25,31,42,48,49,56,62$
$64,79-82,92,104,109,110,129,165]$. The mixing ratio did not interfere, providing the amount of solvent was sufficient to extract all free fat from the powder [17]. The way of stirring greatly influenced the results: the more intense the agitation, the more the solvent could access fat through cracks caused in the powder particle by mechanical stress. The effect was enhanced above an extraction time of $30 \mathrm{~min}$ or more. The more extraction time and temperature increased, viz. $10 \mathrm{~s}$ to $20 \mathrm{~h}$ and 20 to $70{ }^{\circ} \mathrm{C}$ respectively, the more free fat was extracted. Kim et al. [79] confirmed this trend with contact times of $10 \mathrm{~min}, 24$ and $48 \mathrm{~h}$. As an application, different fractions of free fat could be extracted depending on contact time, namely surface free fat, inner free fat from the preceding residue and total free fat $[82,178]$. The kind of powder affected free fat recovery; if homogenization was applied prior to spray drying, extraction time and temperature less impacted the result [17]. Powder characteristics affecting the accessibility to the solvent, namely particle size and porosity, have been little considered when expressing the result. However the amount of free fat extracted was highly correlated with particle size and porosity, -0.70 [163] and 0.94 [21] respectively. This is due to an increase in the surface area to volume ratio for smallest powder particles and to a facilitated solvent access in highly porous powders through pores and capillaries. Only Fäldt [42] applied a correction factor to the amount of free fat extracted, which considered the extraction depth.

\subsubsection{Limits and perspectives}

Few authors gave the reliability of the solvent extraction method they used. The repeatability ranged from 0.1 to $4 \%$ and the reproducibility was $0.45 \%[17,41]$. The method was applied for both liquid and solid products. Could the parameters of the 
former be extrapolated to milk powders? Was free fat totally removable from powder particles of different size and porosity? Moreover a quantification error was evaluated by Buma [17] due to solvent evaporation and retention. Some authors recommended a short washing of the powder particles with solvent at the end of the procedure $[17,79,82,109,110]$, but it can not be applied to short time extraction, viz. surface free fat extraction, because it would be equivalent to an additional extraction. Finally the solvent extraction method itself could lead to enhanced quantification of free fat. Indeed, Evers et al. [41] observed an increased free fat content in raw milk and cream with increasing fat solvent polarity. They attributed it to a deterioration of the MFGM and concluded that free fat was at least partly an artifact. However, using an apolar solvent would prevent fat globules and fat droplets to be damaged because polar solvents are used to solubilize polar lipids and proteins of the interface.

\subsubsection{Conclusion and perspectivesto the solvent extraction method}

Free fat represents surface free fat and a variable fraction of inner free fat depending on the method parameters. Thus, it is not possible to directly compare the studies.

Palanuwech et al. [128] proposed an extraction method based on the recovery of non-emulsified fat in a lipophilic dye and the subsequent quantification by the decrease of the absorbance at $517 \mathrm{~nm}$ measured by spectrophotometry. Indeed, the lipid dye solution (incorporating oil Red O) only diluted the free fat but not the emulsified fat. It could be adapted to fat-filled dairy powders but prior rehydration could artificially damage fat droplets. Furthermore, roller-dried powders are rich in non-enzymatic browning products [98] which could interact with the lipid dye during the measure of absorbance.

\subsubsection{The centrifugation method}

Fink and Kessler [50] separated fat that was no longer protected by the MFGM from emulsified fat by the density difference between the fractions, both in raw milk and raw cream. A two-step centrifugation at $60-65{ }^{\circ} \mathrm{C}$ allowed the recovery of a top oily phase which height indicated the amount of free fat present in the sample [156-158]. It should be more convenient to talk about fat droplets diameters instead of densities referring to the abovementioned Stokes equation (Sect. 2.1.3.). Indeed, this method was not correlated with the solvent extraction one but with fat droplet size. It should then represent the homogenization efficiency $[40,156]$.

\subsubsection{Crystallization properties of free fat}

Vanapalli and Coupland [167] made emulsion models composed by a confectionery coating fat, Tween 20 and water with an oil concentration of 100 to $400 \mathrm{~g} \cdot \mathrm{kg}^{-1}$ [167]. They made observations thanks to differential scanning calorimetry (DSC). DSC is able to measure the amount of heat absorbed or released during phase transitions, e.g. melting, crystallization and glass transition, and allows the subsequent characterization of the changes of state. When the samples underwent successive freezing and heating cycles, an exothermic crystallization peak gradually appeared at a temperature above the initial crystallization of the fat droplet. The authors attributed this phenomenon to a gradual decrease in the amount of emulsified fat and a corresponding formation of free fat which was no longer emulsified.

They reported that free fat could act as impurities or nuclei in the emulsion and led 
to heterogeneous crystallization at a higher temperature than in the native emulsion. However, we think it is unlikely that free fat would come into close contact with the lipid core of fat droplets.

The relative proportion of free fat was deduced from the area under the high temperature exothermic peak. Sampling issues were avoided thanks to an original emulsion stability and a continuous analysis of the same sample undergoing the freezethaw cycles [128]. This method would be usable as an accelerated ageing test for milk powders to appreciate its degradability potential during storage. However two problems would limit the application. First, free fat from fat-filled powders processed with vegetable oils would only be detectable at a temperature in the same range of the crystallization temperature of the residual water, thus interfering with the signal detected by DSC. Furthermore, free fat from fat-filled powders processed with anhydrous milk fat (AMF) would not show one but several exothermic peaks, due to the crystallization feature of AMF. A recent study by Lopez et al. showed that DSC was a reliable method to assess the formation of free fat in Emmental cheese [96].

\subsubsection{X-ray photoemission spectrometry (XPS)}

XPS is a technique that gives the surface composition of a powder particle. It was first developed for dairy powders by Fäldt et al. [49]. The sample undergoes a monochromatic $\mathrm{X}$-ray source $\mathrm{Al} \mathrm{K} \alpha$ which leads to the ionization of the atoms by a photoelectric effect. Electrons with binding energy $\left(\mathrm{E}_{\mathrm{b}}\right)$ inferior to the X-ray photons energy $(\mathrm{h} v)$ are ejected from the atom. The kinetic energy $\left(E_{k}\right)$ resulting from this emission is approximately equivalent to the difference between the photon energy and the binding energy. As $E_{k}$ is specific, it allows the identification of the atoms thanks to the following basic equation:

$$
\mathrm{E}_{\mathrm{k}}=\mathrm{h} v-\mathrm{E}_{\mathrm{b}}-\Phi
$$

where $\Phi$ is the working force of the electrons. Then, matrix formulas allow the quantification of each element in the sample as a percentage $(\mathrm{w} / \mathrm{w})$. A dairy powder is considered to be composed of 3 major elements: lactose, protein and fat. It does not distinguish between free and encapsulated fat (see Fig. 2) but it has been combined with scanning electron microscopy (SEM) of powder particles before and after free fat extraction to support the observations (Fig. 5) [79]. This method gives information from the first $10 \mathrm{~nm}$ of depth, i.e. half the depth of the newly formed membrane after homogenization [146]. Furthermore, given that powder particle surface can be highly irregular, to what extent is it a representative measure?

\subsection{Qualitative methods}

\subsubsection{Free fat composition}

Chromatographic techniques are widely used to characterize lipids. Elements are separated between a mobile and a stationary phase depending on their affinity with each of them. Detection is based on physical and chemical properties of those elements. Thin layer chromatography is a useful technique to separate the major lipids classes, i.e. triacylglycerols, mono and diglycerides, free fatty acids and phospholipids with a high resolution and a short time analysis. The constituents are then available for quantification and identification. Gas chromatography would be adapted to determine the exact fatty acids composition of the free fat fraction and high-pressure liquid chromatography would be useful for the composition of TAG [58]. 

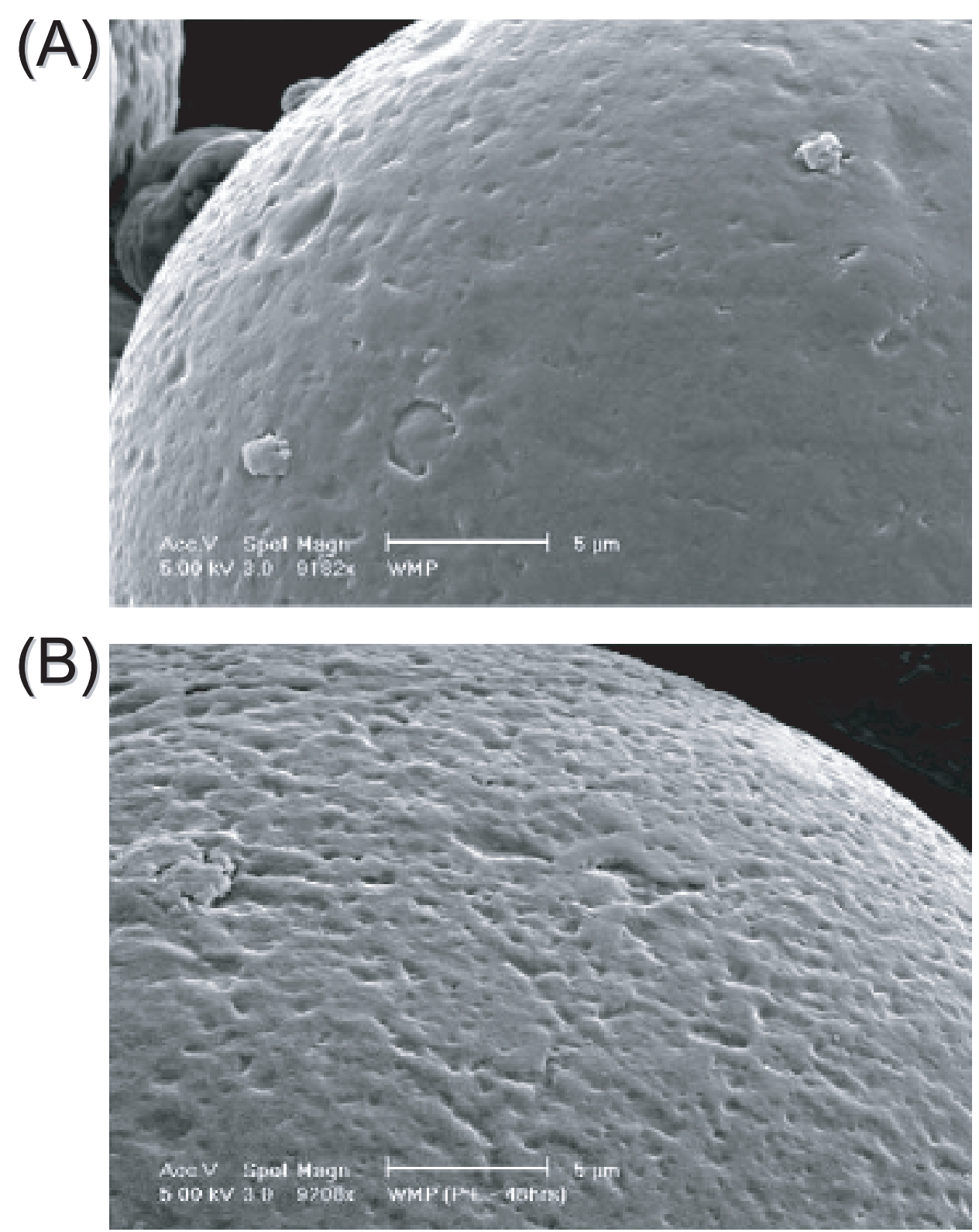

Figure 5. Scanning electron micrographs of the surfaces of industrial spray-dried whole milk powder (A) before and (B) after free fat extraction with petroleum ether for $48 \mathrm{~h}$. Scale bar: $5 \mu \mathrm{m}$. Reprinted from [79] with permission from Elsevier. 


\subsubsection{Thermal properties of free fat}

Thermal properties of fat are related to its TAG composition. DSC allows the determination of extracted free fat thermal properties, namely initial temperature of crystallization, final temperature of melting, crystallization and melting enthalpies, and the comparison with the thermal properties of total fat. If DSC is coupled with $\mathrm{X}$-ray diffraction, TAG polymorphic transitions and packing of TAG molecules in fat crystals can be identified [95, 120]. As mentioned above, free fat seems to initiate crystallization at a higher temperature than emulsified fat $[96,167]$. Indeed, milk fat in bulk needs fewer nuclei to initiate crystallization than milk fat dispersed as fine droplets [177].

\subsubsection{Microscopic observations of the microstructure of powder particles and fat}

\subsubsection{Optical microscopy}

\section{Confocal laser scanning microscopy (CLSM)}

CLSM is a powerful technique that allows the non invasive observation of several elements both at the surface and within the powder particles. Nile blue and Nile red fluorescent probes are commonly used to label fat while Nile blue, Fast green FCF and rhodamine B are used to label protein $[8,13]$. Krypton-argon and heliumneon lasers allow the simultaneous observation of fat and protein; crystallized lactose appears by negative contrast or in the reflective mode [103].

A scanning exploration through successive focal planes of a powder particle can be achieved by realizing optical sections of the sample: morphology of fat, fat droplet size and dispersion at the surface and within the particle are easily observed [13, 90, 103]. Large areas of non globular fat clearly appear at the particles surface and junction of agglomerated powder after a three-dimensional reconstruction from several optical cross-sections [103]. A dynamic and semi-quantitative control of the powder microstructure during process and storage is possible by means of CLSM [8].

\section{Light microscopy}

Buchheim et al. [14] adapted a method which allowed the observation of surface fat both before and after free fat extraction by means of osmium tetroxide labeling.

\subsubsection{Electron microscopy}

\section{Scanning electron microscopy (SEM)}

The powder particles are covered by a thin metallic layer, e.g. gold, which conducts electrons. When the latter impact the sample surface, a particle spectra or radiation is emitted, analyzed and then turned into an image. Extended observations should be avoided at high resolution otherwise the metallic layer and even the powder particles would be damaged [25].

SEM has been used to infer about powder particle structure and size distribution, fat droplets size distribution within the powder particles and presence of fat under its several aspects, i.e. globular or not emulsified.

SEM could reveal structural modifications at the powder particle surface. Kim et al. [79] observed several kinds of dairy powders both before and after free fat extraction with petroleum ether. The whole milk powder surface was rather smooth but showed many clear dents after free fat removal. The authors suggested that it was initially covered by irregular " patches" or "pools" of about $1 \mu \mathrm{m}$ or a layer of surface 
free fat (Fig. 2). The cream powder surface was covered by a thick greasy-looking layer but after extraction, the particles were well separated from one another and many hollow circular features appeared in the particle surface, which were probably initially filled by a thick layer of free fat. Baechler et al. [9] observed the fat droplets repartition and the influence of a heat treatment on fat release and formation of lactose crystals.

Observations within the powder particle were achieved by using a razor blade [25] They revealed a rather porous structure with pores and capillaries, and one or more central vacuoles.

SEM observations were coherent with the physical characteristics of the powders, e.g. wettability, agglomeration and flowability [104]. The resolution was of 5-10 $\mu \mathrm{m}$ order; however, composition elements could not be differentiated unless they adopted a distinct morphology such as droplets or crystals.

\section{Transmission electron microscopy (TEM)}

An electron beam is condensed onto a thin sample section in order to visualize a hologram or the transformed Fourier image of the diffraction image [104]. TEM is of micrometric order resolution but it needs a long and impairing preparation.

The technique has been useful for the observation of protein-protein or proteinfat interactions formed during the process. The most relevant example has been the adsorption of casein micelles on fat droplets after the homogenization step [169] which influenced the emulsion stability [104].

Schmidt and Buchheim [143] observed a thin free fat layer and fat droplets within a powder particle after freeze-etching of the sample.

\subsubsection{Small deformation rheological measurements}

Vanapalli and Coupland [167] used a concentric cylinder Couette flow system as an indirect qualitative method to assess the higher crystallization temperature of free fat as cited in the same above-mentioned study. Peak of the elastic shear modulus $\mathrm{G}^{\prime}$ could indicate a little fraction of free fat acting as a nucleation point of crystallization in the model emulsion.

A wide range of methods are available to directly or indirectly consider free fat and globular fat (Tab. I) but they did not all prove to be relevant and correlated with one another or with physical properties of dairy powders.

\section{INFLUENCE OF THE PRODUCT COMPOSITION}

\subsection{Influence of fat}

\subsubsection{Composition and structure of fat}

\subsubsection{Bulk composition and structure}

\section{Milk fat}

Milk is a natural oil-in-water emulsion where fat is dispersed into spherical fat globules with diameters ranging from 0.2 to $15 \mu \mathrm{m}$ (mean value: $4 \mu \mathrm{m}$ ) [172]. The lipid core of fat globules is constituted of 97 to $98 \%$ by TAG [30]. More than 400 FA have been identified in cow milk; each of them can be located in one of the three positions of the TAG molecule [70]. The theoretical possibilities rise to several thousands of TAG species, but FA are not randomly distributed. Short-chain FA and unsaturated oleic acid (C18:1) are essentially esterified in the $s n-3$ position. It has an impact on the melting point of TAG 
Table I. Types of fat within a powder particle: main associated analytical methods. Identification numbers and letters refer to captions in Figure 2: 1a: layer of surface free fat; $1 \mathrm{~b}$ : patches of surface free fat; 2: inner free fat; 3: surface globular fat; 4: encapsulated fat; 5: coalesced fat. Abbreviations: CLSM: confocal laser scanning microscopy; SEM: scanning electron microscopy; TEM: transmission electron microscopy; XPS: X-ray photoemission spectrometry.

\begin{tabular}{lcc}
\hline $\begin{array}{l}\text { Surface free fat } \\
1 \mathrm{a}+1 \mathrm{~b}\end{array}$ & $\begin{array}{c}\text { Qhort-time solvent-extraction } \\
\text { method with apolar solvent }\end{array}$ & Qualitative method \\
$\begin{array}{l}\text { Total free fat } \\
1 \mathrm{a}+1 \mathrm{~b}+2\end{array}$ & $\begin{array}{c}\text { Solvent-extraction method with } \\
\text { apolar solvent }\end{array}$ & CLSM \\
$\begin{array}{l}\text { Surface fat } \\
1 \mathrm{a}+1 \mathrm{~b}+3\end{array}$ & XPS & SEM before/after extraction \\
$\begin{array}{l}\text { Total fat } \\
1 \mathrm{a}+1 \mathrm{~b}+2+3+4+5\end{array}$ & $\begin{array}{c}\text { Solvent-extraction method with } \\
\text { polar solvent }\end{array}$ & CLSM \\
\hline
\end{tabular}

which has to be liquid at the physiologic temperature of the cow for excretion by the bovine mammary gland. It also influences the digestion of the newborn mammal. For further information about milk lipids, refer to the exhaustive reviews by Christie [30] and Jensen [70].

The secreting mode of fat globules by "budding" implies a three-layered membrane with total thickness ranging from 10 to $20 \mathrm{~nm}$, the so-called "milk fat globule membrane" (Fig. 4A) [39].

The singular three-layered system is a way to maintain the native emulsion in milk, to avoid aggregation and coalescence of fat globules (Fig. 3) and to protect fat against lipolytic enzymes [94]. The MFGM is then a complex arrangement of proteins, glycoproteins, phospholipids, enzymes, diglycerides and traces of monoglycerides, cerebrosides and cholesterol [105]. High-melting TAG are often cited as part of the MFGM but they are just an artifact due to sample preparation [170].

\section{Vegetable oils used in fat-filled dairy powders}

Dairy powders (including infant formulas) often incorporate vegetable oils, alone or as blends, instead of milk fat because of their low cost. Table II gives the FA composition of these oils. Coconut oil is rich in the short-chain FA (C6:0 to C12:0) and poor in unsaturated FA. Corn oil or maize oil is obtained from the germ of corn grain; once refined, it is little affected by oxidation despite its high unsaturated FA content. Palm oil mainly consists of palmitic acid (C16:0), oleic acid (C18:1) and linoleic acid (C18:2). Low-erucic rapeseed oil has a high oleic acid content due to the decrease in erucic acid 22:1 from $490 \mathrm{~g} \cdot \mathrm{kg}^{-1}$ to trace levels; naturally occurring anti-oxidants prevent it from oxidation. Soybean oil is rich in unsaturated FA thus it is prone to fat oxidation. Sunflower oil is extracted from the seeds of the flower heads; its composition varies depending on the varieties and climate [127].

Vegetable oils often undergo technological processing steps to raise their melting point. Consequently, they are less subject to oxidation and they offer more functional food stuff applications. Hydrogenation, interesterification and fractionation are common steps to obtain desired melting points, avoid the formation of trans fatty acids and control chain length of FA respectively [57]. 
Table II. Fatty acids composition of some vegetable oils (in their natural form) used for fat-filled dairy powders. Unsaturated fatty acids appear in grey background (adapted from [57, 127]).

\begin{tabular}{|c|c|c|c|c|c|c|c|c|c|c|c|c|c|}
\hline$\%$ fatty acids & $6: 0$ & 8:0 & 10:0 & 12:0 & 14:0 & $16: 0$ & $16: 1$ & $18: 0$ & $18: 1$ & $18: 2$ & $18: 3$ & 20:0 & 20:1 \\
\hline Coconut oil & 1.3 & 12.2 & 8.0 & 48.8 & 14.8 & 6.9 & NS & 2.0 & 4.5 & 1.4 & NS & 0.1 & NS \\
\hline Corn oil & $\longleftarrow$ & $<0.1$ & $\longrightarrow$ & 0.1 & 0.2 & 13.0 & NS & 2.5 & 30.5 & 52.0 & 1.0 & 0.5 & 0.2 \\
\hline Palm oil ${ }^{1}$ & NS & NS & NS & 0.1 & 1.0 & 44.3 & 0.15 & 4.6 & 38.7 & 10,5 & NS & 0,3 & NS \\
\hline Rapeseed oil $^{2}$ & $\longleftarrow$ & $<0.5$ & $\ldots$ & $\rightarrow$ & $<1.0$ & 4.0 & NS & 2.0 & 56.0 & 26.0 & 10.0 & $\operatorname{tr}$. & 2.0 \\
\hline Soybean oil & $\longleftarrow$ & $<0.1$ & . & 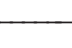 & & 11.0 & 0.5 & 4.0 & 22.0 & 53.0 & 7.5 & 1.0 & 1.0 \\
\hline $\begin{array}{l}\text { Hydrogenated } \\
\text { soybean oil }\end{array}$ & NS & NS & NS & NS & NS & 11.0 & NS & 7.0 & 45.0 & 34.0 & 2.0 & NS & NS \\
\hline Sunflower oil ${ }^{3}$ & $\longleftarrow$ & $<0.4$ & 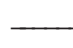 & _ & 0.1 & 5.5 & 0.1 & 4.7 & 19.5 & 68.5 & 0.1 & 0.3 & 0.1 \\
\hline
\end{tabular}

NS: not specified; tr.: traces.

${ }^{1}$ Mean values; ${ }^{2}$ low-erucic acid; ${ }^{3}$ American variety.

\subsubsection{Surface composition}

Surface composition measurements by means of XPS revealed an overrepresentation of fat whatever the initial fat composition in the powder (Tab. III) $[48,49,55,75,79,110,119]$. It was ranging from 40 to $50 \%$ in powders enriched with vegetable oils or milk fat encapsulated with a whey protein/lactose mixture $[44,75]$. Some authors showed that surface composition of spray-dried dairy powders could mainly consist of fat (98\%), then proteins and to a lesser extent lactose [79]. When fat content was low, surface fat was very susceptible to bulk fat composition: from 0 to $50 \mathrm{~g} \cdot \mathrm{kg}^{-1}$, surface fat was ranging from 0 to $35 \%$. Then it rose to $25 \%$ from 50 to $300 \mathrm{~g} \cdot \mathrm{kg}^{-1}$ of initial fat content [119].

Coupling XPS with free fat extraction method, Kim et al. [79] deduced that a spray-dried whole milk powder particle was covered by a free fat layer, then proteins were coating fat droplets. However, free fat and surface fat were not correlated (Tab. III) because free fat also originated from the inner powder particle [48, 49,79].

\subsubsection{Inner distribution of fat}

Confocal microscopy observations of spray-dried whole milk powders indicated that fat droplets, protein and occluded air were entrapped within a continuous amorphous lactose phase [8]. Twomey et al. [163] observed small globular inner fat droplets in low free fat powders. On the contrary, high free fat powders showed a surface free fat layer and an inner degradation of the integrity of fat droplets (Fig. 6A). McKenna [103] attributed the non-globular fat areas to coalescence of fat droplets. Surface free fat was specifically located at the joining points of agglomerated powder particles.

High free fat roller-dried powders were mainly covered by large free fat areas and there were few fat droplets (Fig. 6B) [8]. 

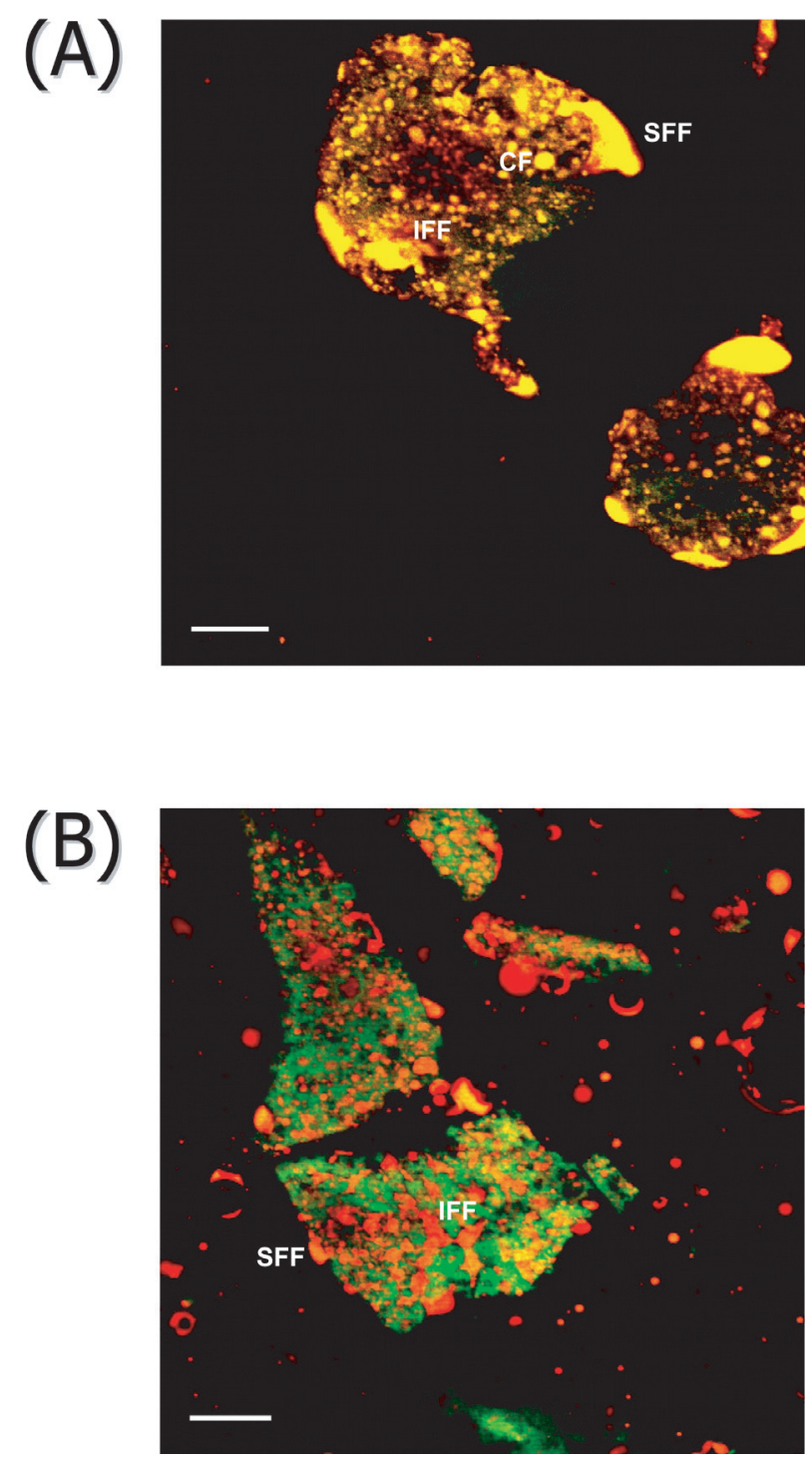

Figure 6. Confocal laser scanning micrographs of whole milk powders. A fluorescent probes mixture incorporating acridine orange for protein and Nile Red for fat was used. Observations were obtained by a Krypton/Argon laser with excitation wavelengths of $488 \mathrm{~nm}$ and $568 \mathrm{~nm}$ for acridine orange and Nile Red respectively. Green indicates protein; red indicates fat. (A) Spray-dried high free-fat powder. Scale bar: $20 \mu \mathrm{m}$. (B) Roller-dried powder with high levels of surface fat. Scale bar: $80 \mu \mathrm{m}$. Abbreviations: CF: coalesced fat; IFF: inner free fat; SFF: surface free fat. 
Table III. Fat composition of various types of dairy powders. Abbreviations: AMF: anhydrous milk fat; DM: dry matter; NCP: native phosphocaseinate; WPC80: whey protein concentrate (protein content of $800 \mathrm{~g} \cdot \mathrm{kg}^{-1}$ ); WPI90: whey protein isolate (protein content of $900 \mathrm{~g} \cdot \mathrm{kg}^{-1}$ ); WMP: whole milk powder.

\begin{tabular}{lccc}
\hline Product & $\begin{array}{c}\text { Bulk composition } \\
\left(\mathrm{g} \cdot \mathrm{kg}^{-1} \mathrm{DM}\right)\end{array}$ & $\begin{array}{c}\text { Surface fat composition } \\
\left(\mathrm{g} \cdot \mathrm{kg}^{-1} \text { surface DM }\right)\end{array}$ & $\begin{array}{c}\text { Free fat } \\
\left(\mathrm{g} \cdot \mathrm{kg}^{-1} \text { powder }\right)\end{array}$ \\
\hline & Röse Gottlieb & Methods & \\
\hline WMP [48,79] & 300,290 & XPS & Apolar solvent \\
Cream powder [79] & 750 & 550,980 & $7-12,28$ \\
Milk powders from skim and & 10 & 170 & 490 \\
full-cream milk powders [119] & 50 & $350-400$ & - \\
& 200 & 550 & \\
Skim milk powder [79] & 300 & $600-650$ & 1 \\
Sodium caseinate + coconut oil [49] & 10 & 180 & 40 \\
& 200 & 500 & 470 \\
NPC [55] & 700 & 700 & - \\
NPC + lactose [55] & 4 & $0\left(145^{*}\right)$ & - \\
NPC + lactose + minerals [55] & 4 & $17\left(167^{*}\right)$ & 11.1 \\
WPI90 + lactose + AMF [75] & 4 & $53\left(187^{*}\right)$ & 48.5 \\
& 202 & 308 & 223.1 \\
WPC80 [79] & 350 & 392 & 2 \\
WPC80 + rapeseed oil [110] & 502 & 494 & 25 \\
\hline
\end{tabular}

* Theoretical composition.

\subsubsection{Thermal properties of fat}

Melting temperatures of milk TAG are ranging from -40 to $40{ }^{\circ} \mathrm{C}$ due to its large range in FA [177]. The melting point of vegetable oils used in the research works varies depending on their FA composition and their hydrogenation degree. It can range from -20 to $60{ }^{\circ} \mathrm{C}$ as mentioned below.

Crystals formed during cooling distort fat globules because of their prominent angles [172]. If milk is submitted to stirring, fat crystals will break the MFGM and provoke partial coalescence of fat globules (Fig. 3) [172]. When cooling kinetic is fast and deep, many nuclei are formed thus leading to small fat crystals [95, 173].

The melting point of milk fat within a powder particle ranged from 10 to $40{ }^{\circ} \mathrm{C}$ when it was measured by DSC [71]. As during spray-drying the temperature of the powder particle ranges from 45 to $90{ }^{\circ} \mathrm{C}$, fat is in a liquid form all along the process.

The more the melting point of fat was above a threshold temperature, the more it was encapsulated $[44,130]$ and the less free fat was extracted [153]. Fäldt and Bergenståhl [44] and Pedersen et al. [130] processed model emulsions with a fat load of $300 \mathrm{~g} \cdot \mathrm{kg}^{-1}$ from various sources, e.g. hardened rapeseed oil, milk fat, hardened coconut oil and soybean oil with melting points of 59,38 , 33 and $-20{ }^{\circ} \mathrm{C}$ respectively. MillqvistFureby [109] studied emulsions made from hardened rapeseed and palm oil, stabilized with sodium caseinate and lactose, of similar composition to whole milk. Encapsulating agents were sodium caseinate, 
lactose alone or associated with maltodextrins. Sloth Hansen [153] processed the emulsions with skim milk concentrates. Fat crystals were able to strengthen the mechanical resistance of the protein/carbohydrate mixture by means of their compacity. However, they deteriorated the powder particle microstructure above a given threshold [44]. Pure fat was always better encapsulated than fat mixtures [109]. Indeed the liquid fraction was released after the disruption of fat droplets due to the presence of fat crystals from the high-melting fraction.

\subsubsection{Total fat content}

Aule and Worstorff [7] determined a positive linear correlation between the fat content of partially skimmed milk powders and the free fat content. Due to the high value of the regression slope, small variations in the total fat content would lead to significant variations of the free fat content. Young et al. [182] attributed this phenomenon to a decreased thickness of the encapsulating coat around the fat droplets. Onwulata et al. [122] confirmed the trend. Free fat increased by $29 \%$ when total fat content rose from 260 to $400 \mathrm{~g} \cdot \mathrm{kg}^{-1}$ [75]. Kelly et al. [74] found a high correlation factor for powders enriched with cream or AMF.

\subsubsection{Source of fat}

AMF was better encapsulated than cream powder in high fat emulsions processed with skim milk powder and added sucrose or starches [122]. Furthermore it gave better flow properties to the powders [121]. When fat was partially watersoluble, e.g. volatile fatty acids, then retention was determined by both molecular diffusion and mobility of the encapsulated element [137].

\subsubsection{Surface-active lipids}

Surface-active molecules such as mono and diglycerides, and soy lecithin (phospholipids) are often added to milk powders in order to enhance their rehydration properties [31]. However, this study did not focus on the effect of these constituents on the formation of free fat.

\subsection{Influence of proteins and their interactions with fat}

\subsubsection{General case}

Dairy proteins are surface-active elements which play an important role in fat/water interfaces during the homogenization step, and then in air/liquid interfaces during drying. The encapsulating phase must show high solubility, good emulsifying properties and must tolerate drying conditions [75]. The fat/water interface has to be stabilized enough by surfaceactive molecules which can form a coat surrounding fat droplets of less than $1 \mu \mathrm{m}$ in diameter (Fig. 4B). It ensures a good emulsion stability and a subsequent protection of fat droplets during drying [162].

The air/liquid interface during drying has an impact on microstructure and composition of the powder particle surface. Fäldt and Bergenståhl [43] considered several ratios of protein/lactose solutions. Surface tension of lactose solutions was greatly affected with as little as $1 \%$ $\mathrm{w} / \mathrm{w}$ in proteins. It increased from -70 to $-40 \mathrm{mN} \cdot \mathrm{m}^{-1}$ with sodium caseinate and to $-50 \mathrm{mN} \cdot \mathrm{m}^{-1}$ with bovine serum albumin. Proteins adsorbed at the air/liquid interface during drying because of their surfaceactive properties. XPS measurements confirmed an over-representation of proteins at the powder particle surface in comparison with their initial content in native protein/lactose mixtures and with powders made from glycine/lactose solutions (glycine is an apolar amino acid). 


\subsubsection{Sodium caseinate and native phosphocaseinate}

\subsubsection{Emulsification step}

Sodium caseinate is amphiphilic and shows good emulsifying properties of fat [62]. XPS measurements verified the efficiency of sodium caseinate/lactose solutions for the encapsulation of several oils with different melting points $[44,45]$. Hogan et al. [62] studied protein concentrations similar to those used in the industry. Fat droplets were coated by a saturated monolayer or an adsorption multilayer when the fat/protein ratio was low. The more the fat/protein ratio decreased in the emulsion, the less the powder particle surface was covered by fat [42].

\subsubsection{Spray-drying step}

The more the solution is concentrated in sodium caseinate, the more encapsulation is efficient. Less than 5\% of surface fat was present in a spray-dried emulsion of similar mass composition to whole milk [45]. Indeed, sodium caseinate accumulated at the air/water interface. The same tendency was observed for native phosphocaseinate (NPC); a 75\% NPC and 25\% lactose solution gave a particle surface composed by $90 \%$ of protein [55]. Confocal microscopy observations confirmed a heterogeneous distribution of casein within the powder particle [90].

For high fat/caseinate ratios, the formation of a dry crust at the particle surface was rather slow, thus allowing the degradation of fat droplets during drying [141]. Indeed, apparent viscosity of the emulsions increased with dry matter (DM) resulting in increased thickness of the encapsulating matrix and decreased vacuole volume [62, 64]. Fat retention was low and led to powder agglomeration. The threshold ratio was fixed at 0.75 with soybean oil; above that limit, fat droplets was prone to destabilization and coalescence. Neither pores nor cracks were visible with SEM whatever the ratio was.

However the fat/caseinate ratio was little correlated with emulsion physical properties. Excess sodium caseinate acted more as a filler in the encapsulating matrix than as a surface-active element in the emulsions. Indeed, it was protected by lactose; this latter strengthened the protein coating at the interface. Sodium caseinate partly lost its emulsifying properties after a heat treatment above $70{ }^{\circ} \mathrm{C}$ (time not specified) [44].

\subsubsection{Whey proteins}

\subsubsection{Emulsification step}

Lee and Rosenberg [91] and Rosenberg and Lee [136] observed protein adsorption in AMF emulsions ranging from 300 to $500 \mathrm{~g} \cdot \mathrm{kg}^{-1}$ of fat by means of SEM and freeze-fracture SEM. They used whey protein isolate (WPI) as an emulsifying agent. The adsorption layer had a granular and aggregated appearance. It showed increasing thickness of 50 to $200 \mu \mathrm{m}$ with successive homogenization steps.

Whey protein concentrate (WPC) adsorbed in a three-layered way: a saturated monolayer, a multilayer and an additional layer when protein content was high [64]. The latter would be due to an increased probability of protein-protein interactions with the subsequent formation of thick viscoelastic layers. Protein content was found to be correlated with the volume-weighted average fat droplet diameter $\left(\mathrm{d}_{4,3}\right)$.

Distortions among the adsorbed protein layer were attributed to mechanical pressure applied by fat crystals (and to sample preparation) [136]. The hypothesis would explain a fat droplet damage observed by Hogan et al. [64] during drying. Furthermore partial desorption of the less concentrated protein layer could lead to fat droplet 
disruption and subsequent release of fat onto the particle surface.

\subsubsection{Spray-drying step}

Surface-active whey proteins mainly accumulated at the air-water interface during drying for both whey protein/lactose solutions and whey protein/lactose/soybean oil emulsions [182].

Whey proteins would be good encapsulating agents for AMF [182]. AMF emulsions stabilized with WPI or WPC showed retention efficiencies of more than $90 \%$. Highly concentrated AMF emulsions $\left(750 \mathrm{~g} \cdot \mathrm{kg}^{-1}\right)$ were efficiently stabilized by as little as $50 \mathrm{~g} \cdot \mathrm{kg}^{-1}$ of WPI [183]. As WPC contained a little fraction of fat, the encapsulating matrix was more hydrophobic than WPI alone thus allowing enhanced diffusion of apolar fat solvent and free fat recovery [183].

However whey proteins would be poor encapsulating agents for vegetable oils such as soybean oil [47]. A model emulsion of similar mass composition to whole milk showed $50 \%$ surface fat instead of $3 \%$ with sodium caseinate. Surface lactose increased too. Nevertheless fat droplet size distribution was preserved along the drying step and powder particle structure was not affected when observed by means of SEM [46].

Lactose acted with whey proteins in the fat droplet size preservation both before and after the drying step, but it did not enhance the encapsulation efficiency [42]. There was no interaction between whey proteins and lactose as opposed to what was observed for sodium caseinate [46].

Soybean oil emulsions stabilized with bovine serum albumin gave high free fat and surface fat powders with increasing heat treatments of the protein [42].

\subsubsection{Conclusion about the role of proteins}

The thicker the adsorption layer, the less fat droplets were susceptible to coa- lescence [62]. Encapsulation efficiency decreased when fat/protein ratio increased. It ranged from 89 to $19 \%$ when the ratio increased from 1:4 to 3:0 for soybean oil stabilized with sodium caseinate. For soybean oil emulsions in WPC75, it decreased from 59 to $4 \%$ when the ratio increased from $1: 4$ to $2: 0$ [64]. It was attributed to (i) a high content of fat in the emulsion and subsequent lack of protein to stabilize the fat/water interface, (ii) a high viscosity which led to deterioration of atomization and (iii) a delayed formation of the dry crust at the powder particle surface and subsequent deterioration of fat droplets [64, 141].

Proteins are costly encapsulating agents compared to carbohydrates. Nevertheless none of them can individually fulfill all required properties; then, research studies mainly focused on protein/carbohydrates mixtures [43, 148, 183].

\subsection{Influence of lactose and other carbohydrates and their interactions with fat}

\subsubsection{Influence of lactose}

\subsubsection{Lactose concentration}

Free fat decreased with increasing lactose/protein ratios [75, 182, 183]. Aguilar and Ziegler [2] found out that lactose concentrations of more than $400 \mathrm{~g} \cdot \mathrm{kg}^{-1}$ were necessary to limit the free fat content. Particles were more spherical, had an even surface and were less porous thus hindering the fat solvent accessibility despite the decrease in the powder particle size and the subsequent increase in the surface area. Keogh and O'Kennedy [75] observed that high lactose/protein ratios, viz. 50:50 for 260 and $400 \mathrm{~g} \cdot \mathrm{kg}^{-1}$ fat loads, decreased both solvent accessibility and fat droplet aggregation during drying. Free fat decreased from 350 to $50 \mathrm{~g} \cdot \mathrm{kg}^{-1}$ fat when the ratio increased from 0:100 to 50:50 [182]. 
This trend was not confirmed by Twomey et al. [163].

Amorphous lactose was supposed to substitute the water during drying. It would protect proteins by forming a hydration coat, hence, keeping them in a solubilized and more stable state [44].

When soybean oil emulsions of $300 \mathrm{~g} \cdot \mathrm{kg}^{-1}$ fat were dried, lactose was necessary to provide a good encapsulation with sodium caseinate, but it remained in the inner parts of the powder particle in contrast to the protein fraction [75, 182, 183]. Moreover, a WPI/lactose matrix had better encapsulation properties than WPI alone when encapsulating a volatile fat [137]. Lactose entrapped the latter by forming an amorphous and glassy phase. The encapsulation of vegetable oils was not improved when adding lactose to WPC [42].

The encapsulation efficiency decreased in the following order: WPC50, WPI95 and WPC75 for a wide range of AMF contents [182]. WPC50 was less susceptible to higher AMF contents than WPI95 because it incorporated lactose; WPC75 was less efficient than WPI95 because it incorporated $80 \mathrm{~g} \cdot \mathrm{kg}^{-1}$ fat in DM content.

Amorphous lactose acted as a hydrophilic filler within powder particles $[182,183]$. It hindered the diffusion of the apolar solvent (such as petroleum ether) within the powder particle, fat accessibility, dissolution of the latter and opposite diffusion of the solvent to get out from the powder particle. As fat diffusion had to be avoided too, amorphous hydrophilic lactose was useful to delay diffusion through the hydrophobic protein coating [75]. Surface fat measured by XPS was not affected by the lactose/protein ratio.

\subsubsection{Lactose crystallization}

Aguilar and Ziegler [3] and Fäldt and Bergenståhl [47] showed that lactose crys- tals damaged the MFGM and the protein coat of fat droplets during processing steps and storage; then they led to coalescence. Lactose is present as a continuous phase in milk [83]. It converts from the glassy to the rubbery state above the glass transition temperature $\left(\mathrm{T}_{\mathrm{g}}\right)$, thus allowing the mobility of the other constituents present in a powder particle and the subsequent release of fat $[89,142,150]$. If a pre-crystallization step was applied before drying, up to $85-95 \%$ or total lactose could be crystallized in the $\alpha$ monohydrate state [66]. The usual tomahawk shape was observed [134].

Once lactose was crystallized, the solvent could diffuse easily and the encapsulation efficiency decreased: indeed, it led to modifications in the porosity of powder particles by the occurrence of newly formed pores $[3,9,42,44,46]$. They originated from the phase separation between lactose and protein.

However, the presence of fat droplets within the powder particle could potentially inhibit lactose crystals growth [42]. It was observed with powders stored at $75 \%$ relative humidity for 4 days despite the presence of $\alpha$-lactose monohydrate crystals detected with calorimetry [45]. Furthermore, the hydrophobic surface fat coverage possibly delayed water uptake which is known to promote lactose crystallization [113]. When the fat content was high, lactose crystallization was delayed and it was necessary to expose the powder to higher water activities to achieve it. The authors attributed it to the higher viscosity due to high fat contents and the necessity to balance it by a higher mobility of the constituents. When lactose crystals were formed during storage, they adopted a needle-like shape [134].

Lactose has adverse effects depending on the processing step under consideration. It enhances fat droplet strength during drying: no coalescence is observed; hence, there is no relevance to filter out lactose 
before drying. As soon as crystallization occurs, it leads to fat release among the powder particle surface and to fat droplet coalescence. However, the amount of lactose necessary to achieve the former is higher than the amount to avoid its negative effect [47].

\subsubsection{Influence of carbohydrates other than lactose}

These ingredients are used for specific applications as encapsulating agents. Few carbohydrates are available for microencapsulation adapted to the food industry. Maltodextrins of several dextrose equivalent (DE) values, modified starch (Mstarch), corn syrup solids (CSS) and natural gums and waxes, e.g. acacia gum and gum arabic, are the most commonly used [138, 162].

\subsubsection{Role during the emulsification step}

Native carbohydrates showed little interfacial properties: they had to undergo structural modifications or they had to be coupled with surface-active agents in order to encapsulate lipidic constituents [62]. Young et al. [183] illustrated that adding surface-active carbohydrates did not distort the stability of an AMF/WPI emulsion. Indeed they showed less efficient emulsification capacities than WPI alone or WPI/non surface-active carbohydrates mixtures. The authors concluded they were poorer emulsifiers of AMF.

\subsubsection{Role during the drying step}

Surface-active carbohydrates with high DE values gave less porous and more homogeneous particles thus decreasing solvent accessibility [63]. Their presence both improved the drying capacities of the encapsulating matrix and enhanced the formation of a dry crust in the boundary parts of the powder particle [148]. The higher the DE value, the less cracks appeared at the powder particle surface by means of SEM, until their complete disappearance. Fat retention was better because the powder was less brittle.

Maltodextrins strengthened the quality of the protein coating on the powder particle surface and limited agglomeration [130]. They affected the surface composition but not the inner structure. Indeed, their crystallization degree and their crystal size are similar to lactose. Emulsions made from vegetable oils, acacia gum and maltodextrins showed a good dispersion of fat droplets within the concentrates [162]. There was no coalescence during drying or agglomeration in the fluidized bed. The encapsulation efficiency decreased in the following order: sucrose, $\mathrm{M}$-starch and $\mathrm{N}$-starch (native starch, i.e. all-purpose flour) [122].

If the protein/carbohydrate ratio increased, the encapsulation efficiency decreased [63, 182, 183]. Indeed, the powder particles were more hydrophobic, thus allowing an enhanced apolar solvent accessibility. In the same way as lactose, WPI/carbohydrates mixtures were more efficient than WPI alone in the encapsulation of AMF with increasing carbohydrate contents [183].

Carbohydrates acted as fillers in the dry matrix that surrounds fat droplets [162]. They gave low-viscosity concentrates that are able to dry quickly. They are chosen depending on the powder properties required, such as solubility, porosity and hygroscopicity.

\subsection{Influence of the mineral elements of milk and their interactions with fat}

No studies about the effect of salts on fat stability in dairy powders were published to our knowledge.

XPS surface composition measurements revealed that carbon, oxygen and 
nitrogen represented $99 \%$ of the total elements detected $[55,119]$. It meant that calcium, sodium and phosphate were present as traces at the powder particle surface.

They could have indirect effects through their association with proteins of the colloidal fraction. Salts decreased electrostatic repulsions between proteins and could lead to interface sharing between fat droplets [10,99]. Furthermore, salts could influence physical properties of powders because of their hydrophilic nature. They could enhance water absorption and its subsequent negative effects. It could also favor powder rehydration as indicated by Gaiani et al. [55] who studied NPC powders.

\subsection{Summary of the composition influence}

Free fat increased with the fat and protein contents and decreased with lactose content [75]. In general terms, free fat decreased with the concentrate dry matter content $[34,35,137]$. A higher dry matter content gave increased encapsulation efficiency because of the presence of a protective film that was formed before the dry crust. Consequently, AMF migration towards the powder particle surface would be limited in the primary steps of drying [182].

However, the authors agreed to say that the fat/protein ratio had little influence on fat retention efficiency if the latter was encapsulated enough by a solid-state matrix [63]. Poor encapsulation efficiency was correlated with a high surface fat content and it resulted in the agglomeration of powder particles.

To conclude with, the two major constituents of the encapsulating matrix had a specific role towards fat. Surface-active proteins stabilized the emulsion: fat was present as small fat droplets well dispersed within the concentrate. Lactose acted as a filler within the powder particle and delayed the extraction of free fat (by an apolar solvent) because of its hydrophilic nature.

\section{INFLUENCE OF THE PROCESSING STEPS}

Before processing, milk undergoes several thermal and mechanical stresses as reviewed by Surel and Ali-HaimoudLekhal [155] and Evers [39]. These stresses would interfere with fat globule resistance to later technological treatments. Stirring had a detrimental effect whatever the storage temperature of raw milk was [157]. Figure 7 illustrates the general process for the manufacture of dairy powders.

\subsection{Processing steps prior to drying}

\subsubsection{Influence of heat treatment}

\subsubsection{Influence of a moderate heat treatment such as pasteurization}

Interactions between fat globules due to association between adsorbed whey proteins could lead to subsequent aggregation during later processing steps [179]. $\beta$-Lactoglobulin (BLG), $\alpha$-lactalbumin (ALA) and $\kappa$-casein associated with the MFGM of whole milk via disulfide bonds above $60{ }^{\circ} \mathrm{C}, 65^{\circ} \mathrm{C}$ and $75^{\circ} \mathrm{C}$ for $10 \mathrm{~min}$, respectively. A heat treatment led to the dissociation of the native BLG dimers into monomers and to the exposure of the thiol groups. Available sulfydryl groups were able to associate and to interchange with other sulfydryl groups and disulfide bonds of the MFGM proteins.

BLG and ALA association with the MFGM increased with higher temperaturetime parameters up to $80{ }^{\circ} \mathrm{C}$. Above this temperature, association was very low, 

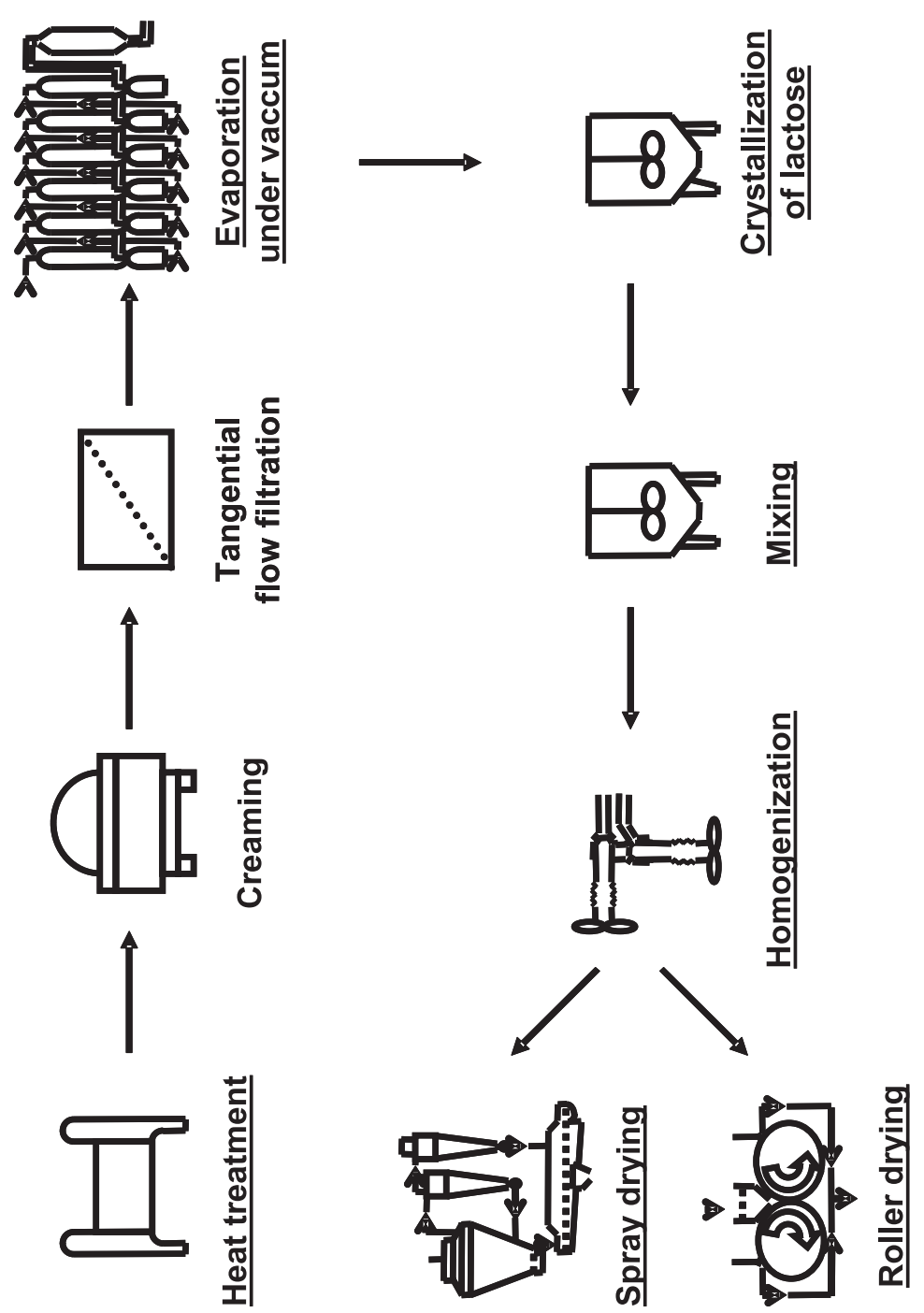

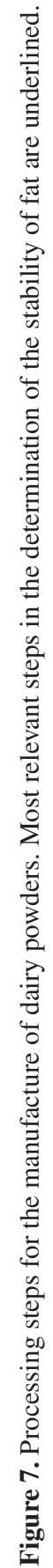


probably because there were no more available sulfydryl groups. The maximum amounts for BLG and ALA were $\sim 1.0 \mathrm{mg} \cdot \mathrm{g}^{-1}$ fat and $\sim 0.2 \mathrm{mg} \cdot \mathrm{g}^{-1}$ fat, respectively. It only stood for $1 \%$ and $0.8 \%$ of the total BLG and ALA in the whey. McPherson et al. [106] compared sodium dodecyl sulfate polyacrylamide gel electrophoresis (SDS-PAGE) patterns of raw and pasteurized milks. They concluded that the MFGM overall composition was little impacted by a pasteurization treatment of $72-74{ }^{\circ} \mathrm{C}$ for $15 \mathrm{~s}$. There was no effect of varying the BLG and ALA contents on their adsorption intensity.

The major native MFGM proteins, e.g. xanthine oxidase and butyrophilin, were intact except heat labile PAS 6 and PAS 7 [179].

If the heat treatment was prior to the homogenization step, whey proteins were less adsorbed and the adsorption layer was less thick [146].

In rapeseed oil emulsions stabilized by WPC80 with or without sodium caseinate, the more proteins were heat-treated before emulsification $\left(60\right.$ to $90{ }^{\circ} \mathrm{C}$ for 0 to $18000 \mathrm{~s}$ ), the more fat droplets size increased [110]. The authors attributed the poorer encapsulation efficiency to a lack of flexibility of the denatured proteins. Moreover, XPS measurements revealed a decrease in the surface protein content after a heat treatment, probably because the diffusion rate of the protein aggregates to the air/liquid interface was slower during the early stage of drying.

\subsubsection{Influence of an ultra high temperature treatment}

Larger free fat contents were found in creams of $300 \mathrm{~g} \cdot \mathrm{kg}^{-1}$ fat when temperature ranged from 115 to $135{ }^{\circ} \mathrm{C}$ irrespective of holding time [51]. The authors attributed it to an enhanced MFGM permeability which led to emulsion instabil- ity. They confirmed the emulsion breakdown in a later study when temperature ranged from 105 to $135{ }^{\circ} \mathrm{C}$ and time from 0.8 to $150 \mathrm{~s}$ [78]. The greatest free fat content was found at $125{ }^{\circ} \mathrm{C}$ regardless of the holding times. Up to $125{ }^{\circ} \mathrm{C}$ the loss of membrane-forming constituents, mainly phospholipids and lipoproteins, was pointed as responsible for the destabilization of the MFGM. Above this temperature, aggregation reactions would lead to a denser and consequently less penetrable MFGM. McPherson et al. [107] underlined the presence of caseins and BLG in SDS-PAGE patterns of isolated membrane materials from UHT milks.

However van Boekel and Folkerts [165] pointed out some limits to the study by Fink and Kessler [51]. An indirect UHT heating could not destabilize fat droplets. Only a UHT direct heat treatment was able to produce disruption of the fat globules and their coalescence in partially skimmed milk (40 $\mathrm{g} \cdot \mathrm{kg}^{-1}$ fat). It was due to turbulent streaming caused by direct steam injection and to cavitation caused by flash vacuum cooling. This trend was enhanced by increased heat temperatures. The authors assimilated the disruption of fat globules during a UHT heating at $140{ }^{\circ} \mathrm{C}$ and homogenization at $10 \mathrm{MPa}$.

Van Boekel and Walstra [166] proposed a review on physical modifications undergone by fat globules and fat droplets in milk after a heat treatment performed before or after a homogenization step.

Millqvist-Fureby et al. [110] observed oil droplet coalescence when a UHT treatment $\left(140{ }^{\circ} \mathrm{C}\right.$ for some seconds) was applied to WPC80 before processing of rapeseed oil emulsions.

\subsubsection{Influence of evaporation}

Water is first removed by steam evaporation under vacuum. Falling film multipleeffect evaporators allow a low energy cost 
and minimal heat-damage to the milk constituents $[175,179]$.

Free fat was greatly enhanced when fat standardization took place after the concentration step. Indeed, the MFGM was disrupted during evaporation because of vapor bubbles formed by boiling while fat was in a liquid state $[112,180]$. Fat was then partly homogenized. Casein micelles were preferentially adsorbed at the BLG onto newly formed interfaces [180]. It resulted in a surface layer similar to a fat globule layer in unheated homogenized milk. Only $\kappa$-casein was directly adsorbed at the surface suggesting that the casein micelle was not damaged during evaporation and remained in its native state to adsorb at the interface. BLG associated more to the MFGM in preheated milk at $95^{\circ} \mathrm{C}$ for $20 \mathrm{~s}$ and when it underwent successive evaporation effects.

Evaporation damaged the protective protein layer around homogenized fat droplets by modifying the fat/water interface, i.e. both its surface area through the creation of small droplets and its composition [175].

\subsubsection{Influence of a pre-crystallization step}

Low variations in excess $\alpha$-lactose led to great variations in the free fat content [156]. When whole milk concentrates were seeded with $1 \%$ lactose, they contained $74 \%$ of $\alpha$-lactose after 5 days. The study gave a correlation coefficient of 0.82 between free fat and excess $\alpha$-lactose (the equilibrium level is $37 \%$ of $\alpha$-lactose at $20{ }^{\circ} \mathrm{C}$ [66]). Schuck et al. [144] undertook a detailed review about factors affecting the lactose crystallization.

Heating a whole milk powder and applying mechanical stresses such as shearing greatly increased lactose crystallization $[87,88]$. The study gave the optimal process parameters to reach the largest lac- tose crystallization with the facility under consideration. Free fat increased from $10 \%$ in the original whole milk powder to more than $95 \%$.

\subsubsection{Influence of the homogenization step}

Homogenization aims at keeping the homogeneity of milk or the dairy mixture [174], by disrupting fat globules into smaller ones: creaming, coalescence and disruption during handling are then delayed. However, aggregation of fat droplets on heating is still possible. There was no influence of homogenizing before or after the evaporation step on the free fat content [74]. The two major effects of homogenization are a strong decrease in fat droplets size and changes in the composition of the protective layer surrounding milk lipids (Fig. 4B) such as a preferential adsorption of caseins, changes after a heat treatment and changes depending on the number of homogenization passes.

\subsubsection{Fat droplets size}

Once homogenized, the fat droplets diameter decreased by a factor of $10(0.2$ to $1 \mu \mathrm{m})$ and the surface area increased from 5 to 15 times ( 7 to $34 \mathrm{~m}^{2} \cdot \mathrm{g}^{-1}$ fat) when compared to the initial one, depending on the process parameters [174].

Fat droplets size decrease was more pronounced when 4 passes were applied instead of 2 for a given pressure of $45 \mathrm{MPa}$, but the free fat content and the surface fat were not influenced [75]. Tamsma et al. [156] observed a decrease in the free fat content when the homogenization pressure increased from 0 to $27.5 \mathrm{MPa}$ in the first stage and 3.5 to $7.0 \mathrm{MPa}$ in the second stage.

Sometimes casein micelles are adsorbed onto two independent fat droplets and form 
the so-called "clusters" [174]. They are generally eliminated through passes in the second stage of the homogenizer if the pressure applied is less than that of the first stage. Large clusters of 10 to $100 \mu \mathrm{m}$ in size increase the emulsion viscosity; this latter accelerates fat droplets aggregation and subsequent creaming. Cluster disruption lead to fat droplets coalescence.

\subsubsection{Preferential adsorption of caseins}

Oortwijn et al. [125], Oortwijn and Walstra [123, 124] and Walstra and Oortwijn [176] published a four-part study on recombined fat droplets. They observed by SEM that caseins adsorbed preferentially to the recombined fat droplets surface. Recombined fat droplets differed from homogenized fat droplets by the absence or quasi absence of native MFGM constituents in the protective layer surrounding the lipids [174].

McPherson et al. [107] observed the presence of $\alpha_{S^{-}}$and $\beta$-casein in SDSPAGE patterns of membrane material isolated from homogenized milks. $\kappa$-casein was little present. A non-selective loss of phospholipids was noted during this technological step. Walstra [171] disclaimed this latter assertion.

Sharma and Dalgleish [145] noticed the adsorption of casein micelles at the newly formed surface after the homogenization of raw milk at $42 \mathrm{MPa}, 40{ }^{\circ} \mathrm{C}$ and 3 passes. Sharma et al. [147] confirmed this trend: casein adsorbed preferentially to the fat/water interface rather than whey protein, regardless of the original amount of protein (Fig. 4B). However the adsorption was enhanced at lower protein contents. Decreasing the colloidal calcium phosphate content destabilized casein micelles and protein load decreased at the fat droplets surface.
The presence of casein micelles at the fat droplet surface was responsible for their stability to creaming and coalescence [166]. The transport of these proteins towards fat was extremely quick (less than $10 \mu$ s under most conditions) [174]. It resulted from convection streams due to intense turbulence caused by homogenizing. Convection favored the adsorption of largest molecules: then, $93 \%$ of the dry matter isolated from the membrane material were caseins. They covered more than $75 \%$ of the surface area. The smaller the fat droplets, the thicker the adsorption layer, with an average thickness of $15 \mathrm{~nm}$. Only 5 to $40 \%$ of the surface area was constituted by original MFGM.

\subsubsection{Influence of a heat treatment after the homogenization step}

Whey proteins adsorbed at the newly formed fat droplets surface when homogenized raw milk was pasteurized at temperature in excess of $70{ }^{\circ} \mathrm{C}$ for $10 \mathrm{~min}$ [145]. Denatured BLG and ALA attached to already adsorbed cysteine-containing caseins, i.e. $\alpha_{\mathrm{S}^{-}}$and $\kappa$-casein, via disulfide bonds. The lipid fraction of heat treated vegetable oil emulsions was well encapsulated regardless of oil type [49]. Then, the adsorption layer was also protective for other fats than dairy ones. It reached a thickness of $34 \mathrm{~nm}$ when milk was homogenized before pasteurization, rather than $20 \mathrm{~nm}$ when milk was homogenized after pasteurization [146]. If heat treatment was intense, fat droplets could aggregate by the association of denatured caseins [165]. Being mainly covered by caseins, fat droplets behaved to some extent like large casein micelles, e.g. they tended to aggregate on heating (heat coagulation) [151, 174]. Adding surface-active molecules, namely phospholipids, before the homogenization step would strengthen their heat stability but would alter their 
stability to coalescence [174]. Furthermore, caseins could lead to fat droplet flocculation during storage (age thickening) and use (feathering in hot coffee) [166]. If milk is to be concentrated, as in the manufacturing of milk powders, it should hence be better to homogenize after the heat treatment [117].

\subsubsection{Influence of the number of passes}

After 2 homogenization passes, emulsion stability depended on electrostatic forces; it was sensitive to the presence of salts such as sodium, potassium, calcium and magnesium. When 4 homogenization passes were achieved, the interface layer was thicker; then, the stability mainly depended on steric forces [99].

Kelly et al. [74] underlined that standard homogenization parameters were not sufficient to stabilize the fat/water and the air/water interfaces of fat-filled powders of 360 to $720 \mathrm{~g} \cdot \mathrm{kg}^{-1}$ fat loads.

Homogenization, similarly to an intensive heat treatment, provokes significant changes in the protective layer surrounding the lipids. The newly formed layer properties differ from the original ones, depending on the adsorbed constituents type and load [107]. It allows the manufacture of low free fat powders from concentrates of less than $500 \mathrm{~g} \cdot \mathrm{kg}^{-1}$ of dry matter content all the more since the homogenization pressure was high [33-35, 109].

\subsubsection{Influence of mixing, stirring, pumping and feeding operations}

Fat globules and fat droplets undergoing a shear stress higher than their surface tension were prone to disruption and subsequent formation of a new reconstituted interface [155]. Koc et al. [87, 88] adapted a continuous mixer in order to preprocess whole milk powders and obtain high free fat contents. Several types of paddles were used for mixing and shearing. Fat was almost totally destabilized.

Stirring, pumping and feeding operations led to the formation of free fat depending on their intensity via selected flows [50]. The negative effect of pumping reached a maximum value at $25^{\circ} \mathrm{C}$ in heat treated creams and almost vanished above $50{ }^{\circ} \mathrm{C}$ when all fat was liquid [78]. Furthermore, turbulence and flow through narrow gaps, e.g. valves, increased shear stresses. The study recommended avoiding mechanical treatments between 15 and $40{ }^{\circ} \mathrm{C}$, which would not be possible in industrial conditions.

Air incorporation enhanced proportionately the negative effect of pumping $[7,78]$.

\subsection{Drying}

\subsubsection{Fundamentals}

Roller-drying is the less costly drying way but it is only used for specific food applications such as in the chocolate industry, because it results in intensive heat treatment [144]. The product is applied as a thin film onto rotating, steam heated drums and water is removed by boiling [98]. Standard roller-dried powders can reach more than $900 \mathrm{~g} \cdot \mathrm{kg}^{-1}$ of free fat in the total fat content. As the time-temperature parameters are high, most of the fat droplets have coalesced during drying [175].

Spray-drying is the most commonly used drying process [98]. The concentrate is atomized at the top of the drying chamber so as to form a spray. Water is removed from the product in a hot and dry air flow. A heat transfer, depending on the temperature gradient, takes place from the air to the product, and a water transfer, depending on the partial pressure gradient, takes place in the opposite way. The temperature of the drying concentrate does not exceed $45^{\circ} \mathrm{C}$ (wet bulb temperature) in a dry 
air at $200{ }^{\circ} \mathrm{C}$, as long as water is removed from the droplet surface and replaced by water coming from the inner. The free fat content of standard spray-dried powders is very low: $10-20 \mathrm{~g} \cdot \mathrm{kg}^{-1}$ in the total fat content [131].

It is worth noting that the several processes taking place during drying are almost instantaneous: formation of the droplet by atomization, contact with the dry air, expansion, coalescence and evaporation [100].

\subsubsection{Spray-drying: influence of the process parameters on the free fat content}

Spray-drying damages the protective layer of fat droplets by modifying the composition of the fat/water interface via the adsorption of caseins and whey proteins [175]. Sliwinski et al. [152] observed a displacement of the $\alpha_{\mathrm{S} 1}$ - and $\beta$-casein by denatured BLG at the adsorption layer. Ye et al. [181] confirmed the increased amount of proteins at the fat droplet surface when studying the influence of drying on the interaction between the constituents and the adsorption layer of fat droplets. However they noted that only caseins adsorbed at the newly formed interfaces. The heat treatment intensity due to drying would not have been high enough in this study to denature whey proteins and to allow their subsequent adsorption. Furthermore, as the surface area of fat droplets increased after drying (their diameter decreased), the surface protein coverage decreased slightly.

\subsubsection{Atomizing device}

The spray is usually obtained by a nozzle or a rotary disc (wheel) [42]. The free fat content was lower in powders that originated from a nozzle [74]. Reducing the nozzle diameter allowed the atomization pressure to increase, which decreased the amount of free fat. Increasing the rotary speed of the wheel had a similar effect because it enhanced the homogenization effect of spraying, except when the concentrate had been already homogenized [34]. The lower the rotary speed, the less the first steps of drying were able to prevent the release of fat from the forming powder particles [129].

\subsubsection{Inlet and outlet temperatures}

The higher the inlet temperature, the smaller the free fat content in the powder $[34,74]$. Indeed, the dry crust at the powder particle surface would be more solid and would delay the solvent accessibility to free fat. Nitrogen gas diffusion was very limited when the inlet temperature rose from 155 to $185{ }^{\circ} \mathrm{C}$. The effect was less pronounced when the concentrate had been homogenized already. Bhandari et al. [12] observed a better retention of volatile compounds with higher inlet temperatures during the encapsulation of flavors. At the same time, the surface volatiles content decreased. Sloth Hansen [153] obtained contradictory results when the inlet temperature increased. The free fat content increased because more capillaries and vacuoles would have formed and fat would be consequently less protected. Tamsma et al. [156] did not observe any influence of inlet temperature, probably because the inlet temperature that they used did not exceed $70{ }^{\circ} \mathrm{C}$. Further investigations would be useful in this area.

Conversely, the free fat content increased with increasing outlet temperatures [74]. The retention of volatile compounds was poorer and they were more present on the powder particles surface [12]. The authors explained that it would be due to the formation of cracks and to the subsequent release of volatiles. 


\subsubsection{Influence of the cyclones}

The amount of surface fat increased when cyclones are used to separate the dry product from the drying air $[42,48]$. The trend was significant after the second cyclone, and was attributed to enhanced mechanical stresses that were able to provoke the release of fat onto the powder particle surface. This was confirmed by XPS whereas free fat extraction did not reveal significant differences once the results were corrected by the extraction depth.

\subsubsection{Influence of the fluid bed}

Powder fluidization occurs when a flow of air (gas) reaches sufficient velocity to support the particles without carrying them away in the air stream [36]. The bed of particles then assumes the characteristics of a boiling liquid. It allows the control of the instant properties of powders and the reduction of the amount of fine particles, the so-called "dusty" [54]. Further agglomeration of particles is obtained by solid bridging between particles, with the powder material or a different material, when spraying water or a solution of agglomerating agent such as maltodextrins and starches respectively.

A two-stage drying facility with an internal fluid bed rather than a one-stage drying facility gave powders with lower free fat contents [33]. However, drying in the fluid bed itself had an adverse effect. It was attributed to the breaking-up of the agglomerates already formed, i.e. to the physical structure of the powder. The study recommended a limit to the final drying temperature at $95{ }^{\circ} \mathrm{C}$ for $4 \mathrm{~min}$. Furthermore, product temperatures far too similar to the melting temperature of the encapsulating matrix gave viscous, humid and sticky powders that tended to agglomerate during storage [36].

Only 12 and $17 \mathrm{~g} \cdot \mathrm{kg}^{-1}$ fat were not encapsulated after the drying chamber and the fluid bed respectively, in powders containing $50 \mathrm{~g} \cdot \mathrm{kg}^{-1}$ fat [162].

\subsection{Storage}

Celestino et al. [28] observed a slight decrease in the free fat content of whole milk powders after the 6th month of storage. It was partly attributed to a formation of a fat-protein complex which was not removable by solvents [35].

Lactose crystallization has been mentioned already (Sect. 4.3.1.2).

Keogh et al. [76] studied the influence of vacuum packaging on spray-dried fish oil powder, in the presence or without nitrogen. The free fat content and the fat globule diameter of the reconstituted powders tended to be lower when vacuum packaging did not include nitrogen. However, the off-flavor score related to oxidation was increased. A contraction factor due to vacuum packaging was not evident from the available data.

Thomas et al. [160] proposed a detailed review on the evolution of physical and functional properties of dairy powders during their storage.

\section{INTERACTIONS BETWEEN COMPOSITION ELEMENTS AND PROCESS STEPS}

\subsection{Properties of the emulsion before and during drying in response to technological treatments and subsequent influence on fat stability}

\subsubsection{Emulsion stability: application to the overall drying process}

\subsubsection{Influence of a heat treatment}

Fink and Kessler [50] attributed the formation of fat aggregates and coalesced 
structures in pasteurized or UHT-treated creams to the presence of free fat. The free fat content was correlated with the increase in the average fat droplets size [51].

\subsubsection{Influence of drying}

Small fat droplets (less than $1 \mu \mathrm{m}$ ) favored emulsion stability, enhanced fat retention of the encapsulated phase and decreased surface-extractible fat $[63,148]$.

Fat droplets underwent a shear stress and would be disrupted again during the atomization step [172]. Smaller droplets of 0.1 to $4 \mu \mathrm{m}$ rather than 0.1 to $10 \mu \mathrm{m}$ in the original emulsion were formed during drying [181]. The authors observed the presence of some very large droplets of 4 to $80 \mu \mathrm{m}$ resulting from coalescence. However the fat droplets size distribution was independent of the fat droplets size of the concentrate before drying.

Emulsion instability led to fat droplet aggregation and to an increased viscosity [174]. The former consequence included two physicochemical hypotheses: (i) when water was removed the droplets came closer to each other and (ii) dehydration of the surface-active constituents promoted interactions between these emulsifier molecules adsorbed onto different droplets [86]. Hence, fat droplets could easily coalesce. Fat migration was thus facilitated during drying and fat was present at the powder particle surface [44].

It, thus, seems of the outmost importance to control fat droplet size and its stability all along the process so as to ensure a good encapsulation of fat [75]. For this reason the oil-in-water emulsion has to be very fine $[182,183]$. Sheu and Rosenberg [148] hypothesized that retention of a volatile fat was enhanced by decreasing fat droplets size in the emulsion.

Several alternatives can be considered. (i) The homogenization step (see Sect. 5.1.4): there was an optimum of successive passes and pressure $[75,136]$.

(ii) The atomization: it had a homogenizing effect depending on the speed of the rotary disc or the atomization pressure [22].

(iii) The kind of proteins and their concentration (see Sect. 4.2): while the protein load was sufficient to stabilize the fat/water interface, there was no influence of the fat/protein ratio. Sharma et al. [147] indicated a minimal protein content of $200 \mathrm{mg}$ for each $\mathrm{mL}$ of fat; under that limit they observed that a percentage of fat was not emulsified when centrifugation was applied to milk.

(iv) The molecular weight and size of the carbohydrates: the more the latter were hydrolyzed, the smaller the fat droplets [148]. However, there was no influence of their surface-active characteristics via the $\mathrm{DE}$ value $[63,183]$.

\subsubsection{Behavior of the emulsion after powder rehydration}

Without homogenization, the rehydrated powder showed a higher content in large fat droplets than the corresponding concentrate otherwise it had a similar size distribution [22].

\subsubsection{Emulsion viscosity}

\subsubsection{Viscosity before drying}

Emulsion viscosity had an influence on fat migration towards the powder particle surface, on powder particle size and on the thickness of the encapsulating matrix surrounding fat droplets [141]. If emulsion was too viscous, spray-drying of the atomized concentrate was slower because the droplets remained large and long. It affected drying because of the creation of a semi-permeable layer at the powder particle surface. Indeed, powder particle size 
increased with increasing dry matter content and it was correlated to the apparent viscosity of the emulsion [62]. It was attributed to (i) an incomplete atomization of the emulsions with very high viscosities; (ii) an agglomeration of the powder particles with each other [119] and (iii) an increased time needed for dry crust formation at the powder particle surface because of the low protein load [141]. It then allowed (i) an extended migration of fat towards the powder particle surface and (ii) an enhanced disruption of fat droplets before the complete creation of the powder particle.

Stability towards coalescence is generally improved by adding high concentrations of carbohydrates to the concentrate before drying. They form a viscous phase surrounding the fat droplets, thus delaying them from coming closer from each other, or they create hydrogen bonds with the surface-active molecules that already adsorbed at fat droplets, thus limiting interactions $[4,5]$.

Furthermore, emulsion viscosity decreased with the average size and the increasing solubility of the constituents forming the encapsulating matrix, i.e. protein and lactose [63]. Selecting lowviscosity encapsulating agents allows to dry high-fat concentrates.

Emulsion viscosity was modified by heat treatments and subsequent changes in its physicochemical features [174]. Indeed denatured proteins that adsorbed at the fat globules increased the viscosity. Furthermore, they tended to bind more water molecules [34].

However, a viscous emulsion delayed fat droplet migration and subsequent aggregation and coalescence [101].

\subsubsection{Viscosity after drying}

The increase in emulsion viscosity after rehydration of powder was attributed to the increase in the volume of the dispersed phase (swelling) [64] or to an aggregation of fat droplets resulting in a bi-modal distribution of their size [136].

It was reduced by an homogenization step (20 MPa), a lower speed of the rotary disc (19600 rather than 31300 r.p.m.) or a lower outlet temperature after the drying chamber (from 70 to $105{ }^{\circ} \mathrm{C}$ ) because proteins adsorbed less and were less denatured [34].

\subsection{Properties of the powder particles in response to technological treatments and subsequent influence on fat stability}

\subsubsection{Creation of a powder particle during drying}

\subsubsection{Macroscopically: from the droplet to the powder particle}

Spray droplet evaporation begins as soon as contact with the dry air is established [100]. Firstly, moisture removal of spray droplets is achieved at a nearconstant rate because droplet surface temperature and partial pressure of vapor are constant. Water migrates from the inner droplet to the surface at a rate sufficient to maintain saturation at the spray droplet surface, by capillary and diffusional mechanisms. The wet-bulb temperature relates to the spray droplet one. Then moisture becomes lower than the so-called "critical moisture content" and its removal rate decreases during the falling-rate period, until drying is completed. Once surface wetness can no longer be maintained, a dry crust gradually forms at the surface.

Reducing the drying time led to the quick creation of a dry crust at the boundary of the powder particle thus enhancing fat retention [182]. Indeed, fat losses appeared at the early stages of drying and 
concerned surface fat droplets or inner fat droplets that were able to migrate towards the surface before the formation of the dry crust. The high turbulence and the evaporation of water at the outer parts of the concentrate droplets would be responsible for those losses. Ye et al. [181] assumed that fat at powder particle surface was not protected by a monolayer of adsorbed proteins. It was released during drying and not during previous processing steps, thus agreeing with Walstra's theory [172] about the impossibility of the presence of free fat in a liquid matrix.

\subsubsection{Microscopically: creation of the powder particle surface}

Kim et al. [80] mentioned three different scenarios on how the surface of the drying droplet is formed during spray-drying.

\section{Formation of a crust or skin}

Charlesworth and Marshall [29] deduced from the drying kinetics that when the outer layer of the powder particle was no longer under saturation conditions, solutes started to be deposited as a solid phase at the drying droplet surface. Masters [100] also mentioned a solid material layer forming at the drying droplet surface.

\section{Solid/solute segregation}

Meerdink [108] studied a ternary food model system made of water, sucrose and sodium caseinate. Evaporation of water from the drying droplet surface caused concentration gradients that led to water diffusion towards the surface and solute diffusion towards the center. The transport velocities depended on the concentration gradients of the solutes and on their diffusion coefficients. The segregation was decreased by a higher initial dry matter content. Powder particle surface would then be covered by the slower constituent, namely free fat [80] but it would need further investigations to support this hypothesis.

\section{Protein adsorption at the air/liquid interface}

The studies by Fäldt [42-49] were based on XPS measurements of the surface composition of spray-dried model solutions. Protein was overrepresented at the powder particle surface due to preferential adsorption to the air/liquid interface because of its surface-active properties.

Kim et al. [80] studied whole milk powders with $400 \mathrm{~g} \cdot \mathrm{kg}^{-1}$ lactose, $310 \mathrm{~g} \cdot \mathrm{kg}^{-1}$ protein and $290 \mathrm{~g} \cdot \mathrm{kg}^{-1}$ fat. After free fat extraction with petroleum ether, surface fat estimated by XPS still reached $68 \%$ (rather than $98 \%$ in the original powder) which would represent fat droplets embedded in a protein coat. SEM observations agreed with XPS measurements. The authors concluded that early segregation of constituents before the formation of a dry crust during drying was the most reliable scenario. They calculated diffusion coefficients thanks to the Stokes-Einstein equation. Free fat and fat droplets had the lower values hence they remained at the surface; then casein micelles, whey proteins, lactose and mineral elements formed the inner parts, from the surface to the core. A previous study already suggested a migration of low molecular weight solutes towards the interior of the drying droplet in response to concentration gradients [29]. Actually, the surface composition would represent the solubility of the constituents found in the drying solution.

A powder particle is formed as soon as the surface reaches the critical concentration which is a function of the solubility 
of constituents at the wet-bulb temperature [38]. Fat was carried out towards the surface during drying or it was already there $[80,119]$. It tended to accumulate all the more since the inlet temperature was high $\left(200\right.$ rather than $\left.120{ }^{\circ} \mathrm{C}\right)$. Later drying steps, e.g. fluidization, probably influenced the surface composition, in addition to drying in the chamber [80]. However, as long as solutes diffusion to the air/water interface was fast enough, drying parameters did not influence powder surface composition to a great extent [48].

Two major phenomena would then occur during the first step of drying (i.e. before the formation of the dry crust): (i) a migration of surface-active components towards the surface and (ii) a diffusion of solutes from the surface to the inner parts of spray droplets [42]. However, these are still hypothesis and it assumes that there is enough time for constituents to migrate during drying.

\subsubsection{Spray-dried and roller-dried powders: comparison of their surface composition}

Fat at the surface of spray-dried whole milk powders could reach $98 \%$ as indicated by XPS measurements [79]. When the powder was enriched with a vegetable oil at a similar fat content as a whole milk powder $\left(260 \mathrm{~g} \cdot \mathrm{kg}^{-1}\right)$, the surface was composed of $50-55 \%$ fat, $30-34 \%$ protein and 15-16\% lactose [42]. Roller-dried powders were mainly covered by fat $(84 \%)$ then protein $(9 \%)$ and lactose (7\%). High denaturation of protein and shape of the particles (large and angular rather than spherical) would be responsible for a poor fat encapsulation.

\subsubsection{Powder particle size}

\subsubsection{Influence of powder particle size on fat retention and the free fat content}

There was an optimal drying droplet size for the encapsulation of fat during the drying process [11]. Larger particles had a lower surface area to volume ratio hence they could encapsulate more fat. On the other hand, the creation of the dry crust was delayed, and there was then a greater loss of volatile substances.

Buma [18] observed that free fat content was higher in smaller particles for a same total fat content. However, Fäldt [42] showed that the free fat content was correlated with differences in powder particles size, regardless of the surface composition and the drying facility. When several heat treatments were applied, neither surface fat measured by XPS nor the free fat content varied, this latter being corrected by the extraction depth. The free fat content was identical wherever the sample was taken, whereas surface fat increased strongly after the second cyclone. These observations contradict again a previous study by Buma [18], who noted a higher free fat content in powder particles originating from the cyclones. It was attributed to a surface area which was the double of that of the particles from the drying chamber.

Actually, free fat extraction could be a complement to XPS analysis. If surface fat is high but free fat is rather low, the surface layer of fat is probably low. On the contrary, if free fat is high too then this layer is probably thicker or inner fat is more reachable by solvents.

\subsubsection{Composition elements affecting powder particle size}

The higher the oil content, the smaller the powder particle size [11]. Indeed, there 
was less available encapsulating agent to diffuse to the interface with the already adsorbed molecules at the monolayer and the overall thickness of the adsorbed multilayers decreased. Furthermore, the surface tension of the drying concentrate decreased, thus impairing the atomization with a two-fluid nozzle [119]. Fat would influence the mechanical properties of the surface dry crust and would limit the expansion of the particle.

Conversely, powder particle size globally increased in a non-linear relationship with the concentrate dry matter content $[38,64]$. It was correlated with the apparent viscosity of the emulsion when fat content increased. Rosenberg et al. [141] observed that powder particles became longer, larger and no more spherical above a given viscosity. However, there could have been agglomerated or stuck-together particles because of the presence of surface fat [64].

\subsubsection{Process elements affecting powder particle size}

Reducing drying droplet size allowed the decrease of the powder particle size [38]. It could be achieved by decreasing the nozzle diameter orifice from 2 to $1.5 \mathrm{~mm}$. Drying droplets size was then $7 \mu \mathrm{m}$ instead of $19 \mu \mathrm{m}$ and powder particles size decreased of 35 to $55 \%$ of its original value. Reducing inlet temperature from 200 to $120{ }^{\circ} \mathrm{C}$ also led to a decrease in powder particle size because the drying particle had time to deflate and shrivel as it cools [119].

\subsubsection{Powder particle microstructure}

Composition of the drying concentrate (including the fat/encapsulating matrix ratio), drying parameters (temperature of dry air, type and speed of atomization) and storage conditions determine powder particle microstructure which in turns is responsible for fat migration during drying and storage [27, 138, 140, 182, 183].

Studies about surface and inner microstructure of powder particles allowed the evaluation of the protection level of fat, its organization, the flowing properties of the overall powder, their porosity and apparent density [140]. SEM was the most commonly used qualitative method to assess particle microstructure $[9,21,25,38$, 42,62-64,72,73,79, 104, 111,113, 122, 129, $136,138,140,143,148,149,169,182,183]$.

\subsubsection{Surface microstructure \\ Composition elements affecting surface microstructure}

Folds, indentations, pores and cracks at the powder particle surface would be due to (i) a mechanical stress induced by irregular drying of the surface areas of the particle which in turns is influenced by atomization and other drying parameters and to (ii) the influence of drying on casein with its subsequent shrinkage [15, 21, 25, 138].

Rosenberg and Young [138] studied the microstructure of microcapsules made of AMF and whey proteins. High contents of AMF limited the shrinkage of the encapsulating matrix. It had been suggested already by Buma [21] for casein.

Presence of surface dents was all the more pronounced since there were less WPI in the encapsulating matrix [149]. The smoothing of surface irregularities was correlated with the viscosity of the drying concentrate by means of its surface tension properties [139, 149]. Indeed, the thermal expansion (under the influence of heat and steam) was able to smooth particle surface provided the drying rate and the viscoelasticity were high enough. The encapsulating matrix became solid more slowly when the WPI content was high and remained probably more elastic. 
Lactose would have an influence given that folds appeared at the particle surface of powders incorporating WPC whereas few dents were present with WPI [138]. Mistry et al. [111] noted that the surface microstructure depended on both protein and lactose contents. Their concomitant presence at concentrations above $200 \mathrm{~g} \cdot \mathrm{kg}^{-1}$ gave powders with wrinkled particles hence with a greater surface area.

The dry matter content could have an effect on the shrinkage of particles during drying: dents were less pronounced when it increased [140].

\section{Influence of powder particle size}

Indentations were more evident on smaller particles because drying time was shorter $[138,149]$. The encapsulating matrix became solid before expansion and the subsequent particle smoothing could occur.

Furthermore, as smaller particles dried and became solid faster, they could collide with still viscous larger ones and remain trapped on their surface [73]. If the latter were no more sticky, the small particles impacts created depressions on their surface.

\section{Process elements affecting surface microstructure}

Higher inlet temperature (210 rather than 150 or $160{ }^{\circ} \mathrm{C}$ ) led to smoother surface aspect particles [138]. The higher the temperature difference between the feed concentrate and the drying air, the smoother the particle surface in relation to the drying kinetics [140].

Slow cooling and higher inside temperature of particles led to inclusion of small particles within their folds.

Finally, the presence of surface dents was due to the composition of the concentrate, its viscosity via its surface tension, and to atomization and drying parameters $[111,138,140]$. They had a negative effect on the flowability and rehydration properties of the powders [139]. The authors still did not find any relation between free and surface fat with the surface microstructure of the particles. However, both have an influence on powder physical properties (see this section and Sect. 6.2.4.).

\subsubsection{Inner microstructure}

\section{Composition elements affecting inner microstructure}

Fat was homogeneously dispersed as very small droplets within the matrix. They had a diameter of 50 to $600 \mathrm{~nm}$ for particles of 1 to $40 \mu \mathrm{m}$ (case of microencapsulation). It was observed for ethyl caprylate encapsulated by gum arabic [140] or by WPI/maltodextrins and WPI/CSS mixtures [148], for AMF encapsulated by WPI, WPC50 and WPC75 [138], or by WPI/lactose, WPI/M-starch and WPI/dextrin mixtures [182, 183]. Fat seemed to be well separated from the outer surface: neither pores nor cracks were detected between inner and outer parts of the particles at the SEM resolution (about $1 \mu \mathrm{m})[9,21,115,138,140]$.

Rosenberg et al. [140] and Rosenberg and Young [138] noted that fat droplets size did not vary from the original emulsion to the powder: there was no coalescence during drying. The matrix protected fat, provided it was not altered during storage. Furthermore, the type of protein did not influence the inner microstructure of powder particles.

\section{Influence of powder particle porosity}

Porosity has an influence on free fat extraction of milk powders via the solvent accessibility [21, 23]. De Vilder et al. [34] found a positive linear correlation between the free fat content and the penetration 
of nitrogen as a measurement of particle porosity. Spray-dried powder particles show one or several interconnected central vacuoles which shape is not influenced by surface folds [21]. Pores and capillaries also form part of powder particles porosity as shown in Figure 2.

The porosity of microcapsules incorporating amorphous lactose would be lower to those without lactose [113]. King [83] mentioned that lactose crystallization led to the formation of thin interstices and cracks around the crystals. Moreau and Rosenberg [113] did not confirm the observation, but they worked with a different matrix.

When AMF was encapsulated in a WPI/lactose matrix, extraction by petroleum ether was promoted after lactose crystallization because the porosity was greater. However, pores in powders stored under humid conditions (water activity $a_{W}$ above 0.43 ) were partially plugged by a partial dissolution of the matrix. The solvent diffused less in the powder particle; furthermore, water created a hydrophilic barrier. Hence, powder porosity resulted from thermal and mechanical stresses during drying and storage: it often decreased, thus influencing the free fat content [24].

\section{Process elements affecting inner microstructure}

Under the same atomization parameters, higher inlet temperatures in the drying chamber led to larger, more numerous central vacuoles [140]. The thickness of the encapsulating matrix was decreased.

The presence of vacuoles was attributed to either air desorption, presence of steam, or both. Shrinkage of the encapsulating matrix due to water losses was counterbalanced by high drying temperatures inducing extended expansion of the air bubbles. Vacuoles were formed during early stages of drying, i.e. prior to shrinkage which occurred when the matrix was still enough elastic.

\subsubsection{Physical properties of dairy powders in relation to free fat and surface fat}

\subsubsection{Oxidation}

Oxidation concerns unsaturated fatty acids, including free fatty acids originating from the lipolysis of fat [160]. Milk lipids first oxidize as hydroperoxydes, which in turns are decomposed into carbonylated products. The latter are responsible for undesirable off-flavors and polymerization with proteins.

It is commonly evaluated by the peroxide value [67] for the primary products of oxidation or by the thiobarbituric acid, fluorescent spectroscopy and size-exclusion liquid chromatography for the secondary products of oxidation [160]. Sensory analysis by an experienced panel can support the physicochemical analysis [75].

Despite surface fat oxidizing more rapidly, oxidation strongly depended on the oxidation degree of the encapsulated fat for the latter represented more than $90 \%$ of the total extractable fat present in a whole milk powder [61]. The more the surface was covered by fat, the more cholesterol oxidized [75] unless it was low-melting fat $[42,56]$. Indeed, liquid fat would partially and temporarily protect cholesterol crystals by spreading over them [150].

Keogh and O'Kennedy [75] claimed free fat and fat oxidation did not depend on the same factors. The free fat content evaluated by solvent extraction was not correlated to oxidation flavors in whole milk powders stored at ambient temperature or at $30{ }^{\circ} \mathrm{C}$, for 6 months and protected from light $[19,42,56]$. However, the taste of the large particle size fractions, which incorporated far less free fat, was found to be better [19]. 
Oxidation depends on oxygen content, the presence of antioxidant molecules, light (mostly UV), metallic ions, storage temperature, relative humidity and water activity $[60,61,102,135,154]$.

Inner porosity of powder particles, i.e. capillaries and vacuoles, constitutes an amount of trapped air that is susceptible to diffusion so as to make contact with fat and oxidize it $[76,116,162]$. Gas displacement pycnometry measurements with a gas of similar molecular dimension to oxygen, e.g. nitrogen, can predict its permeation level [116].

A good dispersion of fat droplets within the solid matrix is essential to avoid the propagation of oxidation to the overall product [162].

\subsubsection{Rehydration properties}

The composition at the air/water interface of drying droplets was more important than the composition at the oil/water interface of emulsion droplets, i.e. the stability and properties of the adsorbed layer [42], mainly the protein-fat (and protein-protein) interactions [27,112]. However, emulsion stability played an indirect role because it could delay coalescence; hence, it favored a good encapsulation [42].

\section{Wettability}

Fäldt [42] mentioned the Washburn equation that describes the penetration rate of a liquid into the capillaries of a powder particle:

$$
\mathrm{d} h / \mathrm{d} t=\left(r^{2} / 8 \eta h\right) \cdot(2 \gamma \cos \theta / r)
$$

where $h$ is the height of liquid in the capillary, $t$ the time, $r$ the capillary radius, $\eta$ the liquid viscosity, $\gamma$ the surface tension of the liquid in the air and $\theta$ the contact angle between the liquid and the powder particle.

The presence of fat made particle surface more hydrophobic and increased the contact angle with water; therefore, deducing it from the Washburn equation, wettability was poorer [47]. Furthermore, particles of different size would have capillaries of various radius $r$; consequently, their wettability would be different.

Gaiani et al. [55] did not find any significant relation between the surface fat and the wetting time of fat-free powders. However, several authors had noted that the presence of surface fat could be used to predict the wettability of powders $[42,79$, $81,82,153]$. Some of them suggested that this property was correlated with the melting point of surface fat but not to the global melting point of fat, in the absence of surface-active constituents $[82,153]$. The lower the melting point temperature, the better the wettability. The wetting time was also negatively correlated to the lactose content at the particle surface [42].

Finally, wettability would be correlated more to the surface composition of powder particles and dispersibility would be due to the presence of hygroscopic elements in the overall composition, i.e. lactose and minerals [55].

\section{Dispersibility}

Dispersibility had a negative but weak correlation with the free fat content [156]. It was slightly improved when the melting point of the dairy fat was lower. By extrapolation, powders would be more easily dispersed at a temperature higher than the melting of the fat they incorporated.

Buma [19] observed a deterioration of dispersibility when the free fat content varied from 0 to $6 \%$. Above that limit, there was no more influence of free fat because only surface free fat would have an influence [23] or homogenization and powder particle size would be the only parameters to directly influence dispersibility. Poor dispersion properties were recently attributed to the presence of surface fat [64]. 


\section{Solubility}

Authors agreed about the negative influence of fat on the solubility properties of powders [19, 112, 133].

The presence of fat droplet clusters was correlated with a poor solubility by means of insolubles detected after powder reconstitution in hot water and coffee [104]. Fat droplet size increased after powder reconstitution for liquid or semi-solid oils all the more since the powder was stored under humid conditions [130]. Coalescence had occurred during drying or rehydration. Indeed, the semi-solid oil incorporated some fat crystals that could damage oil droplets. The trend was slightly pronounced for solid oil and reconstitution properties were little affected. Fat crystals, agglomerated or not, were observed by light microscopy.

High homogenization pressures improved emulsion stability; on the other hand, they increased concentrate viscosity which could reduce the solubility of powders for a given particle size $[19,153]$. Furthermore, adsorbed casein micelles would be less stable than native micelles; hence, solubility was poorer [112].

After the cyclones, powder particles were smaller, showed higher free fat contents and a better solubility [19].

Time of dissolution ranged from 7 to $15 \mathrm{~s}$ for emulsions of similar composition to whole milk [47].

Finally, homogenization (by decreasing the porosity) and powder particle size probably have a greater influence on the solubility properties of the powder than the free fat content. However, the latter would be related to the first two factors [19].

\section{Cream rising, foaming and churning}

Free fat did not promote cream rising and foaming of milk when the powders were rehydrated [19]. Churning was due to the use of non-homogenized concentrates that gave high free fat powders, but again there was no significant correlation with the free fat content.

\subsubsection{Flowability}

There are few studies about powder flowability of fat-filled powders. In comparison with skim milk powder, the prevalence of fat at the surface of whole milk powder, cream powder and whey powder prevented them from good flowing properties [20, 52, 53, 81, 126, 133, 161]. Surface fat was predominant over hygrometry, amorphous lactose and powder particle size. Indeed, the flowability was greatly improved after free fat extraction [81]. Furthermore, only surface fat measured by XPS and surface free fat would have a negative influence on the flowing properties of powders, and not the total free fat or the total fat for a given powder particle size $[20,23,81,121]$.

The flowability of powders with fat contents of 260 and $730 \mathrm{~g} \cdot \mathrm{kg}^{-1}$ fat was altered in the range 5 to $25{ }^{\circ} \mathrm{C}$. Indeed, the melting of fat was responsible for the formation of liquid bridges between particles and their stickiness to one another by attractive capillary forces $[20,52,53$, 126]. A subsequent slow cooling enhanced the cohesion because fat crystallized and strengthened the bridges [133]. These studies agreed with previous observations by Sloth Hansen [153] on vegetable oils with different melting points.

The melting of fat could also make the powder more elastic and malleable [133]. The contact area between particles was greater which enhanced agglomeration.

Crystallized lactose and interactions between denatured caseins also diminished the flowing properties of powders; hence, temperature and relative humidity have to be considered [52, 53, 84, 126, 133]. 


\subsubsection{Chocolate processing applications}

Butterfat can replace at least partly cocoa butter because of its lower cost and its desirable flavors $[6,168]$. Milk chocolate incorporates about $230 \mathrm{~g} \cdot \mathrm{kg}^{-1}$ of whole milk powder [168].

The free fat content determined the Casson viscosity of the chocolate mass: the higher it was, the less the mixture was viscous, thus making it easier to process the chocolate, e.g. during conching $[6,77,164$, $168]$. It was observed for various melting points of fat, e.g. $18,26,35$ and $41{ }^{\circ} \mathrm{C}$ [6].

Furthermore, milk chocolate hardness at ambient temperature was reduced when the free fat content increased [77,92, 164, 168]. The free fraction of fat inhibited the cocoa butter crystallization and its polymorphism under its most stable form. Hence, tempering was conduced at lower temperatures and fat bloom was delayed during storage [92].

Fat fractions behaved in a different way depending whether roller-dried or spraydried powders were considered [6,37]. Indeed the viscosity of the chocolate mass was always lower with the former even if free fat contents were similar. Rheological properties of the chocolate mass are thus conditioned by interfacial properties and microstructure of the dispersed phase, in addition to free fat.

When fat with a melting point of $26{ }^{\circ} \mathrm{C}$ was added in a free form to the other constituents, the chocolate showed a more pronounced "mixed crystallization" of milk fat and cocoa butter [6]. If fat was added to skim milk before drying, the particles were compact and showed a large central vacuole. If fat was atomized later onto powder particles, the latter had a spongy inner structure and free fat remained available at the surface. Roller-dried powders behaved in the same manner.

Adapting the spray-drying process enabled the manufacture of powders with a similar viscosity behavior to roller-dried powders in the chocolate mass $[6,32]$.

\section{CONCLUSION}

Functional properties of dairy powders related to free fat mainly depend on two considerations. Concentrate composition has a great influence through its three major constituents: (i) fat which includes type of fat (milk fat or vegetable oil), melting point, load and surface-active molecules such as phospholipids; (ii) proteins, mostly casein or caseinate and whey proteins, e.g. WPI and WPC; and (iii) lactose or another carbohydrate in their amorphous or crystallized form. Each constituent is dramatically related to one another by physicochemical conditions, which in turn influences their reactivity and morphology. The process identifies four key-steps: homogenization, pre-crystallization of lactose, drying and storage. The latter has a strong impact on the behavior of lactose and fat. Each step determines fat stability in subsequent ones. Finally, composition and process are highly related but few studies focused on the interaction between both, or only considered a little part of the process. Hence, generalities cannot be extrapolated on how composition and process parameters influence free fat content and fat stability during the overall process, which in turn, interfere in some of the applications of dairy powders: off-flavors from oxidation products, poor rehydration and flowing properties. Moreover it gradually appears that the measure of surface fat by means of XPS is a powerful tool to predict and assess functional properties of dairy powders.

Further research should focus on the overall process, i.e. at least from the homogenization step to storage. It should also increasingly consider composition consistent with industrial requirements, the relationship between free and surface fat and 
their consequences on dairy powder properties. This knowledge will ultimately lead to the appraisal of each factor influence, a better understanding of fat migration during drying and storage and finally a better control of the functional properties of dairy powders.

Acknowledgements: The authors thank the association BBA (Bretagne Biotechnologies Alimentaires) for scientific discussions and financial support.

\section{REFERENCES}

[1] Aguilar C.A., Ziegler G.R., Lactose crystallization in spray-dried milk powders exposed to isobutanol, Food Struct. 12 (1993) 43-50.

[2] Aguilar C.A., Ziegler G.R., Physical and microscopic characterization of dry whole milk with altered lactose content. 1. Effect of lactose concentration, J. Dairy Sci. 77 (1994) 1189-1197.

[3] Aguilar C.A., Ziegler G.R., Physical and microscopic characterization of dry whole milk with altered lactose content. 2. Effect of lactose crystallization, J. Dairy Sci. 77 (1994) 1198-1204.

[4] Allison S.D., Randolph T.W., Manning M.C., Middleton K., Davis A., Carpenter J.F., Effects of drying methods and additives on structure and function of actin: Mechanisms of dehydration-induced damage and its inhibition, Arch. Biochem. Biophys. 358 (1998) 171-181.

[5] Allison S.D., Chang B., Randolph T.W., Carpenter J.F., Hydrogen bonding between sugar and protein is responsible for inhibition of dehydration-induced protein unfolding, Arch. Biochem. Biophys. 365 (1999) 289-298.

[6] Attaie H., Breitschuh B., Braun P., Windhab E., The functionality of milk powder and its relationship to chocolate mass processing, in particular the effect of milk powder manufacturing and composition on the physical properties of chocolate masses, Int. J. Food Sci. Technol. 38 (2003) 325-335.

[7] Aule O., Worstorff H., Influence of mechanical treatment of milk on quantities of FFA and free fat in the milk, as well as on the separability of the milk, Annual Bulletin,
Int. Dairy Fed. - Proceedings of the lipolysis symposium 86 (1975) 116-120.

[8] Auty M.A.E., Twomey M., Guinee T., Mulvihill D., Development and application of confocal scanning laser microscopy methods for studying the distribution of fat and protein in selected dairy products, J. Dairy Res. 68 (2001) 417-427.

[9] Baechler R., Clerc M.-F., Ulrich S., Benet S., Physical changes in heat-treated whole milk powder, Lait 85 (2005) 305-314.

[10] Barbut S., Foegeding E.A., Ca2+-induced gelation of pre-heated whey protein isolate, J. Food Sci. 58 (1993) 867-871.

[11] Beristain C.I., Garcia H.S., Vernon-Carter E.J., Spray-dried encapsulation of cardamom (Elettaria cardamomum) essential oil with mesquite (Prosopis juliflora) gum, Lebensm. -Wiss. Technol. 34 (2001) 398401.

[12] Bhandari B.R., Dumoulin E.D., Richard H.M.J., Noleau I., Lebert A.M., Flavor encapsulation by spray drying - Application to citral and linalyl acetate, J. Food Sci. 57 (1992) 217-221.

[13] Blonk J.C.G., van Aalst H., Confocal scanning light microscopy in food research, Food Res. Int. 26 (1993) 297-311.

[14] Buchheim W., Samhammer E., Lembke J., Light-microscopical visualization of fat on the surface of dried milk particles, Milchwissenschaft 29 (1974) 513-517.

[15] Buma T.J., A correlation between free fat content and moisture content of whole milk spray powders, Neth. Milk Dairy J. 22 (1968) 22-28.

[16] Buma T.J., Free fat in spray-dried whole milk. 1. General introduction and brief review of the literature, Neth. Milk Dairy J. 25 (1971) 33-41.

[17] Buma T.J., Free fat in spray-dried whole milk. 2. An evaluation of method for the determination of free fat content, Neth. Milk Dairy J. 25 (1971) 42-52.

[18] Buma T.J., Free fat in spray-dried whole milk. 3. Particle size. Its estimation, influence of processing parameters and its relation to free-fat content, Neth. Milk Dairy J. 25 (1971) 53-72.

[19] Buma T.J., Free fat in spray-dried whole milk. 4. Significance of free fat for other properties of practical importance, Neth. Milk Dairy J. 25 (1971) 88-106.

[20] Buma T.J., Free fat in spray-dried whole milk. 5. Cohesion, determination, influence 
of particle size, moisture content and freefat content, Neth. Milk Dairy J. 25 (1971) 107-122.

[21] Buma T.J., Free fat in spray-dried whole milk. 8. The relation between free-fat content and the particle porosity of spray-dried milk, Neth. Milk Dairy J. 25 (1971) 123140.

[22] Buma T.J., Free fat in spray-dried whole milk. 9. The size distribution of fat globules in concentrated milk and in spray-dried milk, Neth. Milk Dairy J. 25 (1971) 151158.

[23] Buma T.J., Free fat in spray-dried whole milk. 10. A final report with a physical model for free-fat in spray-dried milk, Neth. Milk Dairy J. 25 (1971) 159-174.

[24] Buma T.J., The cause of particle porosity of spray-dried milk, Neth. Milk Dairy J. 26 (1972) 60-67.

[25] Buma T.J., Henstra S., Particle structure of spray-dried milk products as observed by a scanning electron microscope, Neth. Milk Dairy J. 25 (1971) 75-80.

[26] C.N.I.E.L., L'Économie Laitière en Chiffres, CIDIL, Paris, France, 2005.

[27] Caric M., Kaláb M., Effects of drying techniques on milk powders quality and microstructure: a review, Food Microstruct. 6 (1987) 171-180.

[28] Celestino E.L., Iyer M., Roginski H., The effects of refrigerated storage of raw milk on the quality of whole milk powder stored for different periods, Int. Dairy J. 7 (1997) 119-127.

[29] Charlesworth D.H., Marshall W.R., Evaporation from drops containing dissolved solids, AIChE J. 6 (1960) 9-23.

[30] Christie W.W., Composition and structure of milk lipids, in: Fox P.F. (Ed.), Advanced Dairy Chemistry Volume 2 Lipids, Chapman \& Hall, London, UK, 1995, pp. 1-36.

[31] Clarke P.T., Augustin M.A., Manipulation of solvent-extractable fat content of milk powders, Lait 85 (2005) 261-268.

[32] Cribbin M., The spray way, Dairy Ind. Int. 68 (2003) 33.

[33] De Vilder J., Physical properties of whole dried milk prepared by a 2 -stage process, Lait 60 (1980) 561-573.

[34] De Vilder J., Martens R., Naudts M., Influence of process variables on some whole milk powder characteristics, Milchwissenschaft 31 (1976) 396-401.
[35] De Vilder J., Martens R., Naudts M., The influence of the dry matter content, the homogenization and the heating of concentrate on physical characteristics of whole milk powder, Milchwissenschaft 34 (1979) 78-84.

[36] Dewettinck K., Huyghebaert A., Fluidized bed coating in food technology, Trends Food Sci. Technol. 10 (1999) 163-168.

[37] Dewettinck K., Moor H., Huyghebaert A., The free fat content of dried milk products and flow properties of milk chocolate, Milchwissenschaft 51 (1996) 25-28.

[38] Elversson J., Millqvist-Fureby A., Particle size and density in spray drying-effects of carbohydrate properties, J. Pharm. Sci. 94 (2005) 2049-2060.

[39] Evers J.M., The milkfat globule membrane, compositional and structural changes post secretion by the mammary secretory cell. A review, Int. Dairy J. 14 (2004) 661-674.

[40] Evers J.M., The milkfat globule membranemethodologies for measuring milkfat globule (membrane) damage, Int. Dairy J. 14 (2004) 747-760.

[41] Evers J.M., Crawford R., Robinson N., Harding D., McCarthy O., "Free fat" solvent extraction methods damage milkfat globules, Milchwissenschaft 56 (2001) 504-508.

[42] Fäldt P., Surface Composition of SprayDried Emulsions, Ph.D. thesis. Dept. Food Eng., Lund University, Lund, Sweden (1995).

[43] Fäldt P., Bergenståhl B., The surface composition of spray-dried protein-lactose powders, Coll. Surf. A Physicochem. Eng. Aspects 90 (1994) 183-190.

[44] Fäldt P., Bergenståhl B., Fat encapsulation in spray-dried food powders, J. Am. Oil Chem. Soc. 72 (1995) 171-176.

[45] Fäldt P., Bergenståhl B., Changes in surface composition of spray-dried food powders due to lactose crystallization, Lebensm.Wiss. Technol. 29 (1996) 438-446.

[46] Fäldt P., Bergenståhl B., Spray-dried whey protein/lactose/soybean oil emulsions. 1 . Surface composition and particle structure, Food Hydrocoll. 10 (1996) 421-429.

[47] Fäldt P., Bergenståhl B., Spray-dried whey protein/lactose/soybean oil emulsions. 2 . Redispersability, wettability and particle structure, Food Hydrocoll. 10 (1996) 431439. 
[48] Fäldt P., Sjöholm I., Characterization of spray-dried whole milk, Milchwissenschaft 51 (1996) 88-92.

[49] Fäldt P., Bergenståhl B., Carlsson G., The surface coverage of fat on food powders analyzed by ESCA (electron spectroscopy for chemical analysis), Food Struct. 12 (1993) 225-234.

[50] Fink A., Kessler H.G., Determination of free fat in cream for the assessment of damage caused to fat globules by processing, Milchwissenschaft 38 (1983) 330-334.

[51] Fink A., Kessler H.G., The effect of heating on the storage stability of unhomogenized cream (30\%), Milchwissenschaft 40 (1985) 326-328.

[52] Fitzpatrick J.J., Iqbal T., Delaney C., Twomey T., Keogh M.K., Effect of powder properties and storage conditions on the flowability of milk powders with different fat contents, J. Food Eng. 64 (2004) 435444.

[53] Fitzpatrick J.J., Barry K., Cerqueira P.S.M., Iqbal T., O’Neill J., Roos Y.H., Effect of composition and storage conditions on the flowability of dairy powders, Int. Dairy J. 17 (2007) 383-392.

[54] Fuchs M., Turchiuli C., Bohin M., Cuvelier M.E., Ordonnaud C., Peyrat-Maillard M.N., Dumoulin E., Encapsulation of oil in powder using spray drying and fluidised bed agglomeration, J. Food Eng. 75 (2006) 27-35.

[55] Gaiani C., Ehrhardt J.J., Scher J., Hardy J., Desobry S., Banon S., Surface composition of dairy powders observed by X-ray photoelectron spectroscopy and effects on their rehydration properties, Coll. Surf. B Biointerfaces 49 (2006) 71-78.

[56] Granelli K., Fäldt P., Appelqvist L.A., Bergenståhl B., Influence of surface structure on cholesterol oxidation in model food powders, J. Sci. Food Agric. 71 (1996) 7582.

[57] Gurr M.I., Harwood J.L., Frayn K.N., Dietary lipids. Industrial processing may influence the chemical and physical properties of dietary fats either beneficially or adversely, in: Gurr M.I., Harwood J.L., Frayn K.N. (Eds.), Lipid Biochemistry, Blackwell Science, Oxford, UK, 2002, pp. 129-132.

[58] Gurr M.I., Harwood J.L., Frayn K.N., Lipids: definition, isolation, separation and detection, in: Gurr M.I., Harwood J.L., Frayn K.N. (Eds.), Lipid Biochemistry, Blackwell Science, Oxford, UK, 2002, pp. $1-12$.
[59] Gurr M.I., Harwood J.L., Frayn K.N., Lipids as energy stores. The naming and structure of the acylglycerols (glycerides), in: Gurr M.I., Harwood J.L., Frayn K.N. (Eds.), Lipid Biochemistry, Blackwell Science, Oxford, UK, 2002, pp. 93-97.

[60] Hardas N., Danviriyakul S., Foley J.L., Nawar W.W., Chinachoti P., Accelerated stability studies of microencapsulated anhydrous milk fat, Lebensm.-Wiss. Technol. 33 (2000) 506-513.

[61] Hardas N., Danviriyakul S., Foley J.L., Nawar W.W., Chinachoti P., Effect of relative humidity on the oxidative and physical stability of encapsulated milk fat, J. Am. Oil Chem. Soc. 79 (2002) 151-158.

[62] Hogan S.A., McNamee B.F., O'Riordan E.D., O'Sullivan M., Microencapsulating properties of sodium caseinate, J. Agric. Food Chem. 49 (2001) 1934-1938.

[63] Hogan S.A., McNamee B.F., O’Riordan E.D., O'Sullivan M., Emulsification and microencapsulation properties of sodium caseinate/carbohydrate blends, Int. Dairy J. 11 (2001) 137-144.

[64] Hogan S.A., McNamee B.F., O’Riordan E.D., O'Sullivan M., Microencapsulating properties of whey protein concentrate 75 , J. Food Sci. 66 (2001) 675-680.

[65] Holm G.E., Greenbank G.R., Deysher E.F., The effect of homogenization, condensation and variations in the fat content of a milk upon the keeping quality of its milk powder, J. Dairy Sci. 8 (1925) 515-522.

[66] Holsinger V.H., Physical and chemical properties of lactose, in: Fox P.F. (Ed.), Advanced Dairy Chemistry Volume 3 - Lactose, water, salts and vitamins, Chapman \& Hall, London, UK, 1997, pp. $1-38$.

[67] IDF, Standard 74A, Anhydrous milk fat. Determination of the peroxide value, 1991.

[68] IDF, The World Dairy Situation 2005 - Bull. IDF 399, Int. Dairy Federation, Brussels, Belgium, 2005.

[69] J.O.C.E., DIRECTIVE 2001/114/CE DU CONSEIL du 20 décembre 2001 relative à certains laits de conserve partiellement ou totalement déshydratés destinés à l'alimentation humaine - Annexe I: Dénominations et Définitions des Produits, (2002).

[70] Jensen R.G., The composition of bovine milk lipids: January 1995 to December 2000, J. Dairy Sci. 85 (2002) 295-350. 
[71] Jouppila K., Roos Y.H., Water sorption and time-dependent phenomena of milk powders, J. Dairy Sci. 77 (1994) 1798-1808.

[72] Kaláb M., Microstructure of dairy foods. 2. Milk products based on fat, J. Dairy Sci. 68 (1985) 3234-3248.

[73] Kaláb M., Practical aspects of electron microscopy in dairy research, Food Struct. 12 (1993) 95-114.

[74] Kelly J., Kelly P.M., Harrington D., Influence of processing variables on the physicochemical properties of spray dried fat-based milk powders, Lait 82 (2002) 401-412.

[75] Keogh M.K., O’Kennedy B.T., Milk fat microencapsulation using whey proteins, Int. Dairy J. 9 (1999) 657-663.

[76] Keogh M.K., O’Kennedy B.T., Kelly J., Auty M.A.E., Kelly P.M., Fureby A., Haahr A., Stability to oxidation of spray-dried fish oil powder microencapsulated using milk ingredients, J. Food Sci. 66 (2001) 217224.

[77] Keogh M.K., Twomey M., O’Kennedy B.T., Mulvihill D., Effect of milk composition on spray-dried high-fat milk powders and their use in chocolate, Lait 82 (2002) 531-539.

[78] Kessler H.G., Fink A., Physico-chemical effects of pasteurization on cream properties, Bull. Int. Dairy Fed. 271 (1992) 11-17.

[79] Kim E.H.J., Chen X.D., Pearce D., Surface characterization of four industrial spraydried dairy powders in relation to chemical composition, structure and wetting property, Coll. Surf. B Biointerfaces 26 (2002) 197-212.

[80] Kim E.H.J., Chen X.D., Pearce D., On the mechanisms of surface formation and the surface compositions of industrial milk powders, Drying Technol. 21 (2003) 265278.

[81] Kim E.H.J., Chen X.D., Pearce D., Effect of surface composition on the flowability of industrial spray-dried dairy powders, Coll. Surf. B Biointerfaces 46 (2005) 182-187.

[82] Kim E.H.J., Chen X.D., Pearce D., Melting characteristics of fat present on the surface of industrial spray-dried dairy powders, Coll. Surf. B Biointerfaces 42 (2005) $1-8$.

[83] King N., The physical structure of dried milk, Dairy Sci. Abstracts 27 (1965) 91104.
[84] King N., Shimmin P.D., Microscopic observations on the dispersibility of milk powder particles in some organic liquids, J. Dairy Res. 28 (1961) 277-283.

[85] Kitchener J.A., Mussellwhite P.R., The theory of stability of emulsions, in: Sherman P. (Ed.), Emulsion Science, Academic Press, London, UK, 1968, pp. 77-130.

[86] Klinkesorn U., Sophanodora P., Chinachoti P., Decker E.A., McClements D.J., Encapsulation of emulsified tuna oil in two-layered interfacial membranes prepared using electrostatic layer-by-layer deposition, Food Hydrocoll. 19 (2005) 1044-1053.

[87] Koc A.B., Heinemann P.H., Ziegler G.R., A process for increasing the free fat content of spray dried whole milk powder used for confectionery, in: ASAE/CSAE-SCGR Annual International Meeting, Toronto, Ontario, Canada, 1999, p. 1-14.

[88] Koc A.B., Heinemann P.H., Ziegler G.R., A process for increasing the free fat content of spray-dried whole milk powder, J. Food Sci. 68 (2003) 210-216.

[89] Labrousse S., Roos Y.H., Karel M., Collapse and crystallization in amorphous matrices with encapsulated compounds, Sci. Alim. 12 (1992) 757-769.

[90] Lamprecht A., Schafer U.F., Lehr C.-M., Characterization of microcapsules by confocal laser scanning microscopy: structure, capsule wall composition and encapsulation rate, Eur. J. Pharm. Biopharm. 49 (2000) 1-9.

[91] Lee S.Y., Rosenberg M., Microstructure of anhydrous milk fat/whey protein emulsions (Abstract), J. Dairy Sci. 75 (1992) 110.

[92] Liang B., Hartel R.W., Effects of milk powders in milk chocolate, J. Dairy Sci. 87 (2004) 20-31.

[93] Lindquist K., Brunner J.R., Composition of the free fat of spray-dried whole milk (Abstract), J. Dairy Sci. 45 (1962) 661.

[94] Lopez C., Focus on the supramolecular structure of milk fat in dairy products, Reprod. Nutr. Dev. 42 (2005) 497-511.

[95] Lopez C., Bourgaux C., Lesieur P., Bernadou S., Keller G., Ollivon M., Thermal and structural behavior of milk fat. 3. Influence of cooling rate and droplet size on cream crystallization, J. Colloid Interface Sci. 254 (2002) 64-78.

[96] Lopez C., Briard-Bion V., Camier B., Gassi J.Y., Milk fat thermal properties and solid 
fat content in Emmental cheese: a differential scanning calorimetry study, J. Dairy Sci. 89 (2006) 2894-2910.

[97] Lopez C., Camier B., Gassi J.Y., Development of the milk fat microstructure during the manufacture and ripening of Emmental cheese observed by confocal laser scanning microscopy, Int. Dairy J. 17 (2007) 235-247.

[98] Mahaut M., Jeantet J., Brulé G., Schuck P., Les produits industriels laitiers, Lavoisier Tec et Doc, Paris, France, 2000.

[99] Masson G., Jost R., A study of oil-inwater emulsions stabilized by whey proteins, Colloid Polym. Sci. 264 (1986) 631638.

[100] Masters K., Spray-Air Contact, Particle Formation and Drying, in: Spray Drying in Practice, SprayDryConsult International ApS, Charlottenlund, Denmark, 2002, pp. 180-215.

[101] McClements D.J., Comments on viscosity enhancement and depletion flocculation by polysaccharides, Food Hydrocoll. 14 (2000) 173-177.

[102] McCluskey S., Connolly J.F., Devery R., O'Brien B., Kelly J., Harrington D., Stanton C., Lipid and cholesterol oxidation in whole milk powder during processing and storage, J. Food Sci. 62 (1997) 331337.

[103] McKenna A.B., Examination of whole milk powder by confocal laser scanning microscopy, J. Dairy Res. 64 (1997) 423-432.

[104] McKenna A.B., Lloyd R., Munro P., Singh H., Microstructure of whole milk powder and of insolubles detected by powder functional testing, Scanning 21 (1999) 305-315.

[105] McPherson A.V., Kitchen B.J., Reviews of the progress of dairy science: the bovine milk fat globule membrane - its formation, composition, structure and behaviour in milk and dairy products, J. Dairy Res. 50 (1983) 107-133.

[106] McPherson A.V., Dash M.C., Kitchen B.J., Isolation and composition of milk fat globule membrane material. I. From pasteurized milks and creams., J. Dairy Res. 51 (1984) 279-287.

[107] McPherson A.V., Dash M.C., Kitchen B.J., Isolation and composition of milk fat globule membrane material. II. From homogenized and ultra heat treated milks, J. Dairy Res. 51 (1984) 289-297.

[108] Meerdink G., Drying of liquid food droplets. Enzyme inactivation and multi- component diffusion, Drying Technol. 13 (1993) 483-485.

[109] Millqvist-Fureby A., Characterisation of spray-dried emulsions with mixed fat phases, Coll. Surf. B Biointerfaces 31 (2003) 65-79.

[110] Millqvist-Fureby A., Elofsson U., Bergenståhl B., Surface composition of spray-dried milk protein-stabilised emulsions in relation to pre-heat treatment of proteins, Coll. Surf. B Biointerfaces 21 (2001) 47-58.

[111] Mistry V.V., Hassan H.N., Robison D.J., Effect of lactose and protein on the microstructure of dried milk, Food Struct. 11 (1992) 73-82.

[112] Mol J.J., The milk fat globule membrane and the solubility of whole milk powder, Neth. Milk Dairy J. 29 (1975) 212-224.

[113] Moreau D.L., Rosenberg M., Microstructure and fat extractability in microcapsules based on whey proteins or mixtures of whey proteins and lactose, Food Struct. 12 (1993) 457-468.

[114] Moreau D.L., Rosenberg M., Oxidative stability of anhydrous milkfat microencapsulated in whey proteins, J. Food Sci. 61 (1996) 39-43.

[115] Moreau D.L., Rosenberg M., Porosity of whey protein-based microcapsules containing anhydrous milkfat measured by gas displacement pycnometry, J. Food Sci. 63 (1998) 819-823.

[116] Moreau D.L., Rosenberg M., Porosity of microcapsules with wall systems consisting of whey proteins and lactose measured by gas displacement pycnometry, J. Food Sci. 64 (1999) 405-409.

[117] Muir D.D., UHT-sterilized milk concentrate: a review of practical methods of production, J. Soc. Dairy Technol. 37 (1984) 135-141.

[118] Mulder H., Walstra P., Creaming and separation, in: Mulder H., Walstra P. (Eds.), The milk fat globule. Emulsion science as applied to milk products and comparable foods, Commonwealth Agricultural Bureaux (Farnham Royal) - Pudoc, BucksWageningen, UK, 1974, pp. 139-162.

[119] Nijdam J.J., Langrish T.A.G., The effect of surface composition on the functional properties of milk powders, J. Food Eng. 77 (2006) 919-925.

[120] Ollivon M., Keller G., Bourgaux C., Kalnin D., Villeneuve P., Lesieur P., DSC and 
high resolution X-ray diffraction coupling, J. Thermal Anal. Calorimetry 85 (2006) 219-224.

[121] Onwulata C.I., Smith P.W., Craig J.C., Holsinger V.H., Physical properties of encapsulated spray-dried milkfat, J. Food Sci. 59 (1994) 316-320.

[122] Onwulata C.I., Smith P.W., Cooke P.H., Holsinger V.H., Particle structure of encapsulated milkfat powders, Lebensm.-Wiss. Technol. 29 (1996) 163-172.

[123] Oortwijn H., Walstra P., The membranes of recombined fat globules. II. Composition, Neth. Milk Dairy J. 33 (1979) 134-154.

[124] Oortwijn H., Walstra P., The membranes of recombined fat globules. IV. Effects on properties of the recombined milks, Neth. Milk Dairy J. 36 (1982) 279-290.

[125] Oortwijn H., Walstra P., Mulder H., The membranes of recombined fat globules. I. Electron microscopy, Neth. Milk Dairy J. 31 (1977) 134-147.

[126] Özkan N., Walisinghe N., Chen X.D., Characterization of stickiness and cake formation in whole and skim milk powders, J. Food Eng. 55 (2002) 293-303.

[127] Padley F.B., Gunstone F.D., Harwood J.L., Occurrence and characteristics of oils and fats. Major vegetable fats, in: Gunstone F.D., Harwood J.L.,Padley F.B. (Eds.), The Lipid Handbook, Chapman and Hall Ltd, New York, Cambridge, UK, 1986, pp. 55112.

[128] Palanuwech J., Potineni R., Roberts R.F., Coupland J.N., A method to determine free fat in emulsions, Food Hydrocoll. 17 (2003) 55-62.

[129] Pauletti M., Amestoy P., Butter microencapsulation as affected by composition of wall material and fat, J. Food Sci. 64 (1999) 279-282.

[130] Pedersen G.P., Fäldt P., Bergenståhl B., Kristensen H.G., Solid state characterisation of a dry emulsion: a potential drug delivery system, Int. J. Pharm. 171 (1998) 257-270.

[131] Pisecký J., 20 years of instant whole milk powder, Scandi. Dairy Inf. 2 (1990) 1-5.

[132] Platon J.F., Emulsions et mousses alimentaires, in: Graille J. (Ed.), Lipides et corps gras alimentaires., Tec et Doc Lavoisier, Paris, France, 2003, pp. 317-354.

[133] Rennie P.R., Chen X.D., Hargreaves C., Mackereth A.R., A study of the cohesion of dairy powders, J. Food Eng. 39 (1999) 277-284.

[134] Roetman K., Crystalline lactose and the structure of spray-dried milk products as observed by scanning electron microscopy, Neth. Milk Dairy J. 33 (1979) 1-11.

[135] Romeu-Nadal M., Chavez-Servin J.L., Castellote A.I., Rivero M., Lopez-Sabater M.C., Oxidation stability of the lipid fraction in milk powder formulas, Food Chem. 100 (2007) 756-763.

[136] Rosenberg M., Lee S.L., Microstructure of whey protein/anhydrous milkfat emulsions, Food Struct. 12 (1993) 267-274.

[137] Rosenberg M., Sheu T.Y., Microencapsulation of volatiles by spray-drying in whey protein-based wall systems, Int. Dairy J. 6 (1996) 273-284.

[138] Rosenberg M., Young S.L., Whey proteins as microencapsulating agents. Microencapsulation of anhydrous milkfat structure evaluation, Food Struct. 12 (1993) $31-41$.

[139] Rosenberg M., Kopelman I.J., Talmon Y., A scanning electron microscopy study of microencapsulation, J. Food Sci. 50 (1985) 139-144.

[140] Rosenberg M., Talmon Y., Kopelman I.J., The microstructure of spray-dried microcapsules, Food Microstruct. 7 (1988) 1523.

[141] Rosenberg M., Kopelman I.J., Talmon Y., Factors affecting retention in spray-drying microencapsulation of volatile materials, J. Agric. Food Chem. 38 (1990) 1288-1294.

[142] Saltmarch M., Labuza T.P., Influence of relative humidity on the physico-chemical state of lactose in spray-dried sweet whey powders, J. Food Sci. 45 (1980) 12311236.

[143] Schmidt D.G., Buchheim W., The application of electron microscopy in dairy research, J. Microsc. 167 (1992) 105-121.

[144] Schuck P., Bouhallab S., Durupt D., Vareille P., Humbert J.P., Marin M., Spray drying of wheys and derivatives, Lait 84 (2004) 243-268.

[145] Sharma S.K., Dalgleish D.G., Interactions between milk serum proteins and synthetic fat globule membrane during heating of homogenized whole milk, J. Agric. Food Chem. 41 (1993) 1407-1412.

[146] Sharma S.K., Dalgleish D.G., Effect of heat treatments on the incorporation of milk 
serum proteins into the fat globule membrane of homogenized milk, J. Dairy Res. 61 (1994) 375-384.

[147] Sharma R., Singh H., Taylor M.W., Recombined milk: factors affecting the protein coverage and composition of fat globule surface layers, Aust. J. Dairy Technol. 51 (1996) 12-16.

[148] Sheu T.Y., Rosenberg M., Microencapsulation by spray drying ethyl caprylate in whey protein and carbohydrate wall systems, J. Food Sci. 60 (1995) 98-103.

[149] Sheu T.Y., Rosenberg M., Microstructure of microcapsules consisting of whey proteins and carbohydrates, J. Food Sci. 63 (1998) 491-494.

[150] Shimada Y., Roos Y.H., Karel M., Oxidation of methyl linoleate encapsulated in amorphous lactose-based food model, J. Agric. Food Chem. 39 (1991) 637-641.

[151] Singh H., Sharma R., Taylor M.W., Creamer L.K., Heat-induced aggregation and dissociation of protein and fat particles in recombined milk, Neth. Milk Dairy J. 50 (1996) 149-166.

[152] Sliwinski E.L., Lavrijsen B.W.M., Vollenbroek J.M., van der Stege H.J., van Boekel M.A.J.S., Wouters J.T.M., Effects of spray drying on physicochemical properties of milk protein-stabilised emulsions, Coll. Surf. B Biointerfaces 31 (2003) 219-229.

[153] Sloth Hansen P., Production of agglomerated fat-filled powder, J. Soc. Dairy Technol. 33 (1980) 19-23.

[154] Stapelfeldt H., Nielsen B.R., Skibsted L.H., Effect of heat treatment, water activity and storage temperature on the oxidative stability of whole milk powder, Int. Dairy J. 7 (1997) 331-339.

[155] Surel O., Ali-Haimoud-Lekhal D., Milk fat: composition and modification after industrial treatments, Rev. Méd. Vét. 150 (1999) 681-690.

[156] Tamsma A., Edmondson L.F., Vettel H.E., Free-fat in foam dried whole milk, J. Dairy Sci. 42 (1959) 240-250.

[157] Te Whaiti I., Fryer T., Factors influencing the release of free fat in raw milk, N. Z. J. Dairy Sci. Technol. 11 (1976) 91-95.

[158] Te Whaiti I., Fryer T., The influence of free fat on lipolysis in milk, N. Z. J. Dairy Sci. Technol. 11 (1976) 273-274.
[159] The Truyen T., Orsi F., Fatty acid composition of free and bound fat in milk powders [refDie Fettsäure-Zusammensetzung des freien und gebundenen Fettes von Milchpulvern] (Abstract), Nahrung 21 (1977) 37-43.

[160] Thomas M.E.C., Scher J., Desobry-Banon S., Desobry S., Milk powders ageing: effect on physical and functional properties, Crit. Rev. Food Sci. Nutr. 44 (2004) 297-322.

[161] Tuohy J.J., Some physical properties of milk powders, Ir. J. Food Sci. Technol. 13 (1989) 141-152.

[162] Turchiuli C., Fuchs M., Bohin M., Cuvelier M.E., Ordonnaud C., Peyrat-Maillard M.N., Dumoulin E., Oil encapsulation by spray drying and fluidised bed agglomeration, Innovative Food Sci. Emerging Technol. 6 (2005) 29-35.

[163] Twomey M., Keogh M.K., O’Kennedy B.T., Auty M.A.E., Mulvihill D., Effect of milk composition on selected properties of spray-dried high-fat and skim-milk powders, Ir. J. Agric. Food Res. 39 (2000) 7994.

[164] Twomey M., Keogh M.K., O’Kennedy B.T., Mulvihill D., Seasonal effects of some milk powder characteristics on the rheology of milk chocolate, Ir. J. Agric. Food Res. 41 (2002) 105-116.

[165] van Boekel M.A.J.S., Folkerts T., Effect of heat treatment on the stability of milk fat globules, Milchwissenschaft 46 (1991) 758-765.

[166] van Boekel M.A.J.S., Walstra P., Physical changes in the fat globules in unhomogenized and homogenized milk, Bull. Int. Dairy Fed. 238 (1989) 13-16.

[167] Vanapalli S.A., Coupland J.N., Emulsions under shear - the formation and properties of partially coalesced lipid structures, Food Hydrocoll. 15 (2001) 507-512.

[168] Verhey J.G.P., Physical properties of dried milk in relation to chocolate manufacture, Neth. Milk Dairy J. 40 (1986) 261-268.

[169] von Müller H.R., Electron-microscopical examination of milk and milk products. I. Examination of the structure of milk powders, Milchwissenschaft 19 (1964) 345356.

[170] Walstra P., High-melting triglycerides in the milk fat globule membrane: an artefact?, Neth. Milk Dairy J. 28 (1974) 3-9.

[171] Walstra P., Some comments on the isolation of fat globule membrane material, J. Dairy Res. 52 (1985) 309-312. 
[172] Walstra P., Physical chemistry of milk fat globules, in: Fox P.F. (Ed.), Advanced Dairy Chemistry Volume 2 - Lipids, Chapman \& Hall, London, UK, 1995, pp. 131-178.

[173] Walstra P., Jenness R., Lipids, in: Walstra P., Jenness R. (Eds.), Dairy Chemistry and Physics, John Wiley \& Sons, New York, USA, 1984, pp. 58-97.

[174] Walstra P., Jenness R., Milk Fat Globules, in: Walstra P., Jenness R. (Eds.), Dairy Chemistry and Physics, John Wiley \& Sons, New York, USA, 1984, pp. 254-300.

[175] Walstra P., Jenness R., Properties of Milk Concentrates, in: Walstra P., Jenness R. (Eds.), Dairy Chemistry and Physics, John Wiley \& Sons, New York, USA, 1984, pp. 301-335.

[176] Walstra P., Oortwijn H., The membranes of recombined fat globules. III. Mode of formation, Neth. Milk Dairy J. 36 (1982) 103113.

[177] Walstra P., van Vliet T., Kloek W., Crystallization and rheological properties of milk fat, in: Fox P.F. (Ed.), Advanced Dairy Chemistry Volume 2 - Lipids, Chapman \& Hall, London, UK, 1995, pp. 179-211.
[178] Westergaard V., Milk powder technology Evaporation and spray-drying, A/S NIRO ATOMIZER, Copenhaguen, Denmark, 1983.

[179] Ye A., Singh H., Taylor M.W., Anema S.G., Interactions of whey proteins with milk fat globule membrane proteins during heat treatment of whole milk, Lait 84 (2004) 269-283.

[180] Ye A., Singh H., Taylor M.W., Anema S.G., Interactions of fat globule surface proteins during concentration of whole milk in a pilot-scale multiple-effect evaporator, J. Dairy Res. 71 (2004) 471-479.

[181] Ye A., Anema S.G., Singh H., Behaviour of homogenized fat globules during the spray drying of whole milk, Int. Dairy J. 17 (2007) 374-382.

[182] Young S.L., Sarda X., Rosenberg M., Microencapsulating properties of whey proteins. 1. Microencapsulation of anhydrous milk fat, J. Dairy Sci. 76 (1993) 2868-2877.

[183] Young S.L., Sarda X., Rosenberg M., Microencapsulating properties of whey proteins. 2. Combination of whey proteins with carbohydrates, J. Dairy Sci. 76 (1993) 2878-2885. 